\title{
Sea ice thickness, freeboard, and snow depth products from Operation IceBridge airborne data
}

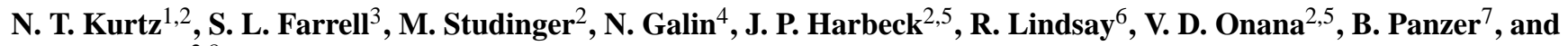 \\ J. G. Sonntag 2,8 \\ ${ }^{1}$ Morgan State University, Baltimore, MD, USA \\ ${ }^{2}$ Cryospheric Sciences Laboratory, NASA Goddard Space Flight Center, Greenbelt, MD, USA \\ ${ }^{3}$ Earth System Science Interdisciplinary Center (ESSIC), University of Maryland, College Park, MD, USA \\ ${ }^{4}$ University College London, London, UK \\ ${ }^{5}$ ADNET Systems Inc., Lanham, MD, USA \\ ${ }^{6}$ Polar Science Center, Applied Physics Laboratory, University of Washington, Seattle, WA, USA \\ ${ }^{7}$ Center for Remote Sensing of Ice Sheets, University of Kansas, Lawrence, KS, USA \\ ${ }^{8}$ EG\&G Technical Services/NASA Goddard Space Flight Center/Wallops Flight Facility, Wallops Island, VA, USA
}

Correspondence to: N. T. Kurtz (nathan.t.kurtz@nasa.gov)

Received: 16 October 2012 - Published in The Cryosphere Discuss.: 15 November 2012

Revised: 30 May 2013 - Accepted: 31 May 2013 - Published: 4 July 2013

\begin{abstract}
The study of sea ice using airborne remote sensing platforms provides unique capabilities to measure a wide variety of sea ice properties. These measurements are useful for a variety of topics including model evaluation and improvement, assessment of satellite retrievals, and incorporation into climate data records for analysis of interannual variability and long-term trends in sea ice properties. In this paper we describe methods for the retrieval of sea ice thickness, freeboard, and snow depth using data from a multisensor suite of instruments on NASA's Operation IceBridge airborne campaign. We assess the consistency of the results through comparison with independent data sets that demonstrate that the IceBridge products are capable of providing a reliable record of snow depth and sea ice thickness. We explore the impact of inter-campaign instrument changes and associated algorithm adaptations as well as the applicability of the adapted algorithms to the ongoing IceBridge mission. The uncertainties associated with the retrieval methods are determined and placed in the context of their impact on the retrieved sea ice thickness. Lastly, we present results for the 2009 and 2010 IceBridge campaigns, which are currently available in product form via the National Snow and Ice Data Center.
\end{abstract}

\section{Introduction}

The determination of sea ice properties from remote sensing data has been a long sought-after goal through the utilization of a wide variety of instruments and field campaigns (e.g., Wadhams et al., 1991; Comiso et al., 2003; Cavalieri et al., 2006; Leuschen et al., 2008; Haas et al., 2010). Data on sea ice properties from satellite altimetry missions have been used to study the behavior of sea ice at regional to global scales (e.g., Laxon et al., 2003; Giles et al., 2008a; Kwok et al., 2009; Farrell et al., 2009; Zwally et al., 2008; Kurtz et al., 2011; Kurtz and Markus, 2012), while data from airborne remote sensing missions have been used to validate satellite data (e.g., Kurtz et al., 2008; Connor et al., 2009; Connor et al., 2012; Laxon et al., 2013) and identify new ways to extend the range of sea ice properties that can be studied using satellite remote sensing data (e.g., Kurtz et al., 2009). The sea ice properties that remote sensing data sets can retrieve depend on the type of instruments used. A key area of interest is the use of altimetry data for the study of sea ice thickness. With this in mind, a fundamental goal of the ongoing NASA Operation IceBridge mission is to utilize a suite of instruments including radar and laser altimeters to engage in large-scale surveys of Arctic and Antarctic sea ice on an annual basis. Operation IceBridge is an airborne mission with its primary 
goal being to create a laser altimetry time series bridging the end of the ICESat mission in 2009 and the launch of ICESat2 currently scheduled for 2016 .

The scale of the IceBridge mission in terms of the number of instruments flown, areal coverage, and number of active campaigns makes it one of the largest airborne missions to date in the polar regions and will enable a new generation of research to be conducted using the data sets. A key aspect of this study is to describe the retrieval of geophysical data products from the Level 1 instrument data, which can then be used by others wishing to engage in more specialized research, as well as to discuss the known limitations and uncertainties of the derived geophysical data products. Here we focus on three products that can be obtained from the IceBridge data set: (1) sea ice freeboard, which is here defined as the height of the snow plus sea ice surface above the water level to be consistent with the laser altimetry data set, (2) snow depth, and (3) sea ice thickness. First, sea ice freeboard is the property retrievable by airborne and satellite altimeters and provides the capability for sea ice thickness studies from the data sets. Moreover, it has been shown to be useful as an independent parameterization for energy balance studies because of the unique relationship between freeboard, sea ice thickness, and the thermal conductivities of snow and ice (Kurtz et al., 2011). Second, knowledge of snow depth is useful for studies of precipitation trends and variability, melt pond coverage, and is also needed for the retrieval of sea ice thickness from altimeter data sets. Third, sea ice thickness is a long sought-after property which is important for the study of a large number of climate variables. Knowledge of this property will allow for an assessment of the stability and variability of the global sea ice cover, which is a component and indicator of global climate change (Lemke et al., 2007).

Previous studies using IceBridge data over sea ice have focused on algorithm development and validation (Farrell et al., 2012; Kwok et al., 2012), exploration of instrument behavior and retrieval issues (Kwok et al., 2011), and comparisons to climatological data (Kurtz and Farrell, 2011). However, the variable nature of aircraft campaigns means that the methods described in previous studies do not necessarily apply to all of the past and future IceBridge data sets. For example, changes to the radar antennas and electronics means that algorithms developed for snow depth retrieval for the 2009 data set (e.g., Kurtz and Farrell, 2011) do not automatically apply to future data sets. Additionally, the distribution of leads and collocated laser altimetry data for sea surface height retrievals along the IceBridge flight tracks also changes year to year and means that the uncertainty of the retrieved freeboard and ice thickness data is variable along the flight paths, rather than a constant value. The addition of new instruments and instrument configuration modifications allows for retrievals using different and improved methodologies on a year-to-year basis. Essentially, the IceBridge data set has and will continue to evolve in time as instrument changes are made to improve the quality of science re-

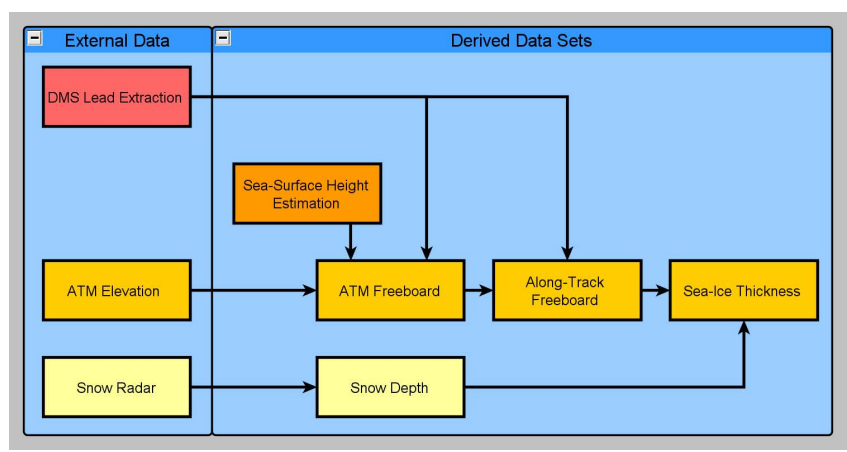

Fig. 1. Flow chart of processing steps to retrieve sea ice thickness from the instrument data.

trievals from the raw instrument data. In this study, we outline the steps that have been utilized for the retrieval of sea ice properties for the 2009 and 2010 data sets, show how variations in the retrieval algorithms have changed as a result, and discuss the applicability of the new algorithms to the 2011 and later data sets. We also present uncertainty estimates due to variations in the sea ice properties, instrument, and inter-campaign algorithm changes. Our goal is to provide a baseline reference that describes the main procedures for producing a continuous time series of sea ice properties and associated uncertainties for the past and future IceBridge campaigns. The derived data products described in this work can be accessed via the National Snow and Ice Data Center at http://nsidc.org/data/idcsi2.html (Kurtz et al., 2012).

A wide variety of instruments and retrieval methods are outlined in this study. Some parameters rely on a single instrument and retrieval method, while others involve multiple instruments and algorithms. A flow chart describing the retrieval of geophysical data products of interest is shown in Fig. 1, which can be referenced throughout the text. The study is organized as follows: Sect. 2 describes the instrument data sets. Sections 3, 4, and 5 respectively describe the approaches used to retrieve sea ice freeboard, snow depth, and sea ice thickness. Each section also includes a discussion of error sources due to instrument issues and inter-campaign algorithm changes. Section 6 describes the results of the freeboard, snow depth, and sea ice thickness data sets for the 2009 and 2010 IceBridge campaigns. The main results of the study are discussed and summarized in Sect. 7.

\section{Data sets}

Here we provide an overview of the instruments and data and their function in the IceBridge mission. A list of instruments and their purpose is provided in Table 1. A map of the 2009 and 2010 IceBridge flight lines and specific flight numbers referred to throughout the text is shown in Fig. 2. 
Table 1. List of instruments used and their function.

\begin{tabular}{lcc}
\hline Instrument & Geophysical properties retrieved & Nominal spatial resolution [m] \\
\hline Airborne Topographic Mapper (ATM) & Sea surface height, freeboard & 1 \\
Snow radar & Snow depth & 15 \\
CAMBOT & Ice type & 0.2 \\
Digital Mapping System (DMS) & Ice type & 0.1 \\
KT-19 infrared pyrometer & Surface temperature & 130 (for a 1 Hz sampling rate) \\
\hline
\end{tabular}
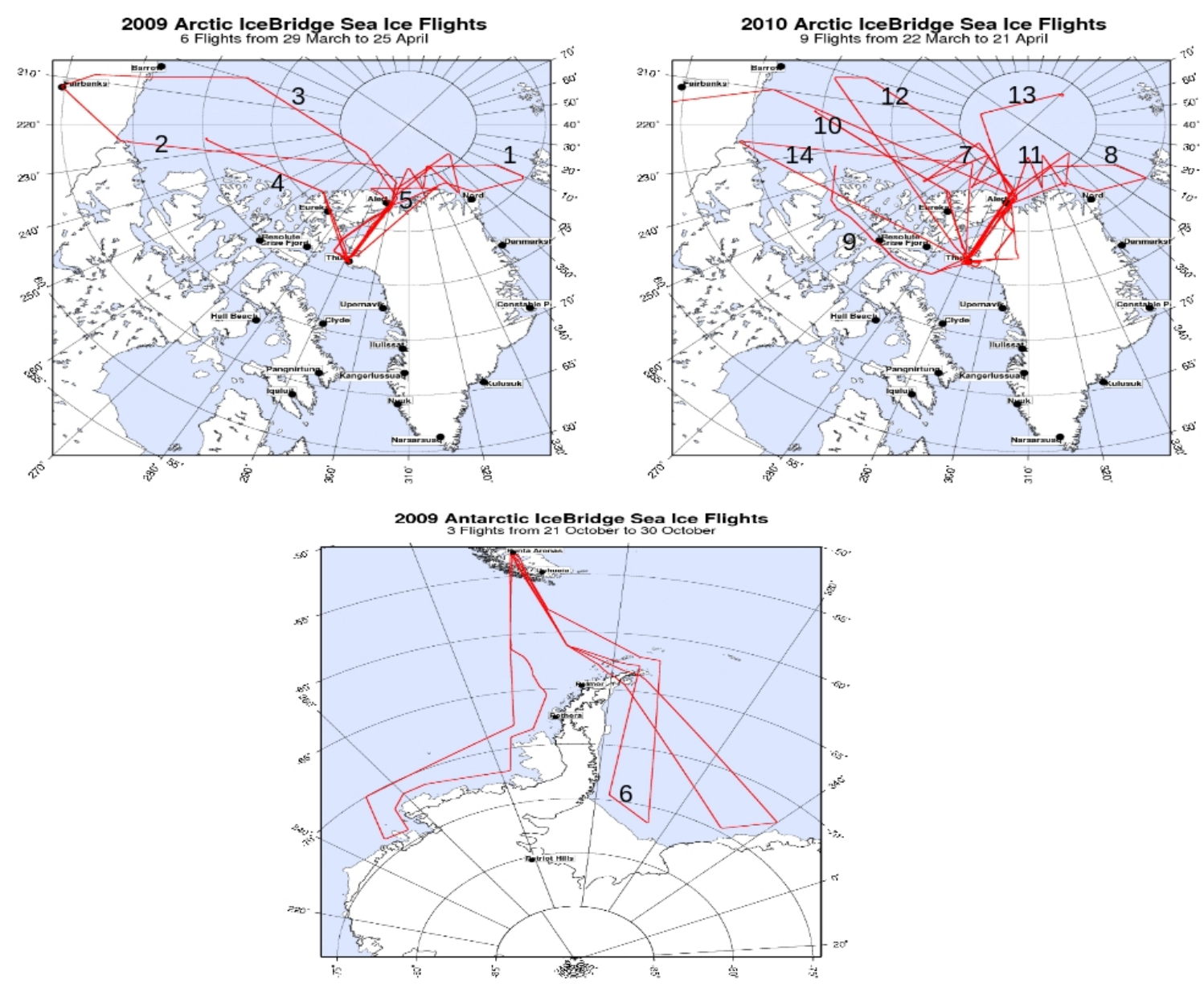

Fig. 2. Maps of flight lines for the 2009-2010 Arctic and 2009 Antarctic IceBridge campaigns. Numbers on the map correspond to the different flights designated in the text and in Table 5.

\subsection{Laser altimetry data}

The laser altimetry measurements used in this study are from the Airborne Topographic Mapper (ATM) (Krabill, 2009a). The ATM is a $532 \mathrm{~nm}$ wavelength conically scanning laser altimeter, combined with a differential GPS system for aircraft positioning and an inertial navigation system (INS) to measure aircraft orientation. The laser range, GPS position, and INS orientation measurements are used to assign three-dimensional geographic coordinates to the point where each laser pulse reflects from the surface. The ATM data are referenced to the ITRF-2005 reference frame and projected onto the WGS-84 ellipsoid. The 15-degree scanner used during the missions yields a measured swath width of approximately half of the aircraft's altitude above the surface. The footprint size of each individual elevation measurement is $\sim 1 \mathrm{~m}$, which is set by the laser beam divergence. The system is calibrated using independent ranging measurements with the system on the ground, and by overflights of presurveyed ground areas. Absolute elevation accuracy from the ATM is usually about $10 \mathrm{~cm}$ or better (Krabill et al., 1995) with geolocation accuracies of better than $1 \mathrm{~m}$ (Schenk et al., 1999). Specifically for the IceBridge campaigns, Martin et al. (2012) estimate the parameters of the ATM system to be 
Table 2. Modeled sea surface height data sources.

\begin{tabular}{lc}
\hline Parameter & Data source \\
\hline$h_{\text {geiod }}$ & EGM2008 \\
$h_{\text {ocean }}$ & TPXO6.2 \\
$h_{\text {load }}$ & TPXO6.2 \\
$h_{\text {earth }}$ & ATM processing (see text) \\
$h_{\text {pressure }}(\Delta P)$ & ECMWF Interim reanalysis \\
\hline
\end{tabular}

(1) $74 \mathrm{~cm}$ horizontal accuracy, (2) $6.6 \mathrm{~cm}$ vertical accuracy, and (3) $3 \mathrm{~cm}$ vertical precision.

Using ground test calibration data, Kwok et al. (2012) identified a bias in the ATM data for low amplitude signals due to the leading edge fit procedure used for elevation retrievals. The bias will impact the freeboard retrievals when points with a low signal strength are used. We have applied the polynomial fit correction factor described in Kwok et al. (2012) to correct for these biases. No correction was applied for points with a signal strength higher than 950 (the ATM signal strength is not radiometrically calibrated and is thus reported as dimensionless data numbers) since the polynomial fit diverges beyond this point. A different laser system was operated during the 2010 Arctic and 2009 Antarctic campaigns, thus we have applied a similar correction generated from ground calibration data specific for these campaigns. The correction, $h_{\mathrm{e}-\mathrm{corr}}$ (in unit of meters), is an 8th order polynomial fit of calibration data provided by the ATM team that is added to the ATM elevation data:

$$
\begin{aligned}
& h_{\mathrm{e}-\mathrm{corr}}=1.356 \times 10^{-26} r_{\mathrm{s}}^{8}-1.51483 \times 10^{-22} r_{\mathrm{s}}^{7} \\
& +7.48991 \times 10^{-19} r_{\mathrm{s}}^{6}-2.16621 \times 10^{-15} r_{\mathrm{s}}^{5} \\
& +3.97857 \times 10^{-12} r_{\mathrm{s}}^{4}-4.61175 \times 10^{-9} r_{\mathrm{s}}^{3} \\
& +3.17998 \times 10^{-6} r_{\mathrm{s}}^{2}-0.00118755 r_{\mathrm{s}}+0.2
\end{aligned}
$$

where $r_{\mathrm{S}}$ is the ATM received signal strength. This polynomial was chosen to correct for biases to the level of points with a received signal strength of 1100 , which was the modal signal strength during the 2010 Arctic campaign. A constant correction of $0.008 \mathrm{~m}$ is added to points with a received signal strength greater than 2500 to correspond to the calibration data set and account for divergence of the polynomial fit beyond this level. The range calibration data and derived $h_{\text {e-corr }}$ correction factor are shown in Fig. 3a, and histograms of the received signal strength values are shown in Fig. 3b. The signal strength has a mean of 931 and standard deviation of 387 for the 2009 campaign, and a mean of 1064 and standard deviation of 397 for the 2010 campaign. For the 2009 campaign, the mean value of the bias correction over sea ice covered points is 0.005 and $0.023 \mathrm{~m}$ over leads. For the 2010 campaign, the mean value of the bias correction is $0.003 \mathrm{~m}$ over sea ice covered points and $0.032 \mathrm{~m}$ over leads.
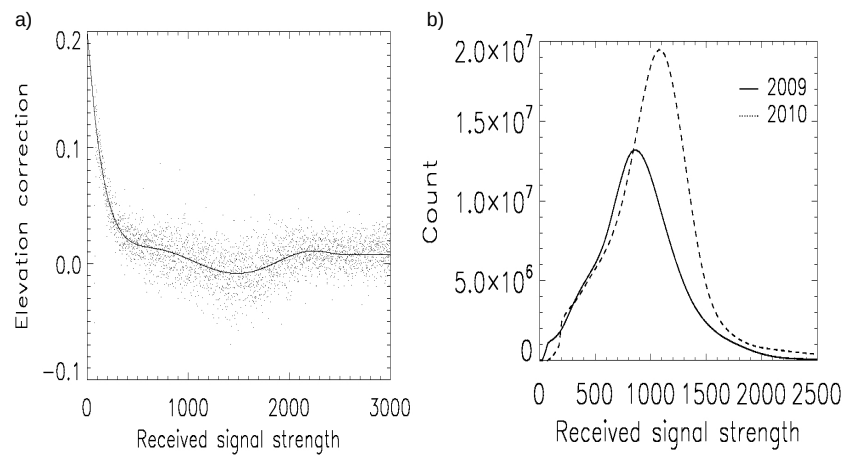

Fig. 3. (a) Dependence of received signal strength on measured range to a fixed target for the 2010 ATM instrument. Black dots are the mean elevation bias for each unit of signal strength. The black line is the subsequent correction factor that was added to the ATM elevations used in this study for a particular signal strength. (b) Histogram of ATM received signal strength values for the 2009 and 2010 Arctic campaigns.

\subsection{Snow radar}

Snow depth was measured using a frequency-modulated, continuous-wave (FMCW) radar that utilizes dechirp on receive (Leuschen, 2009; Panzer et al., 2013). Mixing a delayed, attenuated receive signal with a copy of the transmit signal returns a beat frequency equal to the product of the chirp rate (bandwidth divided by pulse length) and the twoway delay time to the target. During the 2009 campaign, the radar transmitted 2.5 to $7 \mathrm{GHz}$ with a $270 \mu$ s pulse length and $2 \mathrm{kHz}$ pulse repetition frequency. During the 2010 campaign, the radar transmitted 2.0 to $6.5 \mathrm{GHz}$ with a $250 \mu$ s pulse length and $2 \mathrm{kHz}$ pulse repetition frequency. Four hardware presums (also referred to as coherent averaging or stacking) are performed prior to writing data to disk with an additional four presums done in post-processing. Processed radar data are provided in 33 second segments along the flight path, spanning $4.2 \mathrm{~km}$ for the nominal aircraft speed $\left(460 \mathrm{~km} \mathrm{hr}^{-1}\right)$.

The snow radar system measures the return radar signal as a function of time, which is scattered from the area illuminated beneath the aircraft. Snow depth is determined by detecting the snow-air and snow-ice interfaces within the radar waveform and multiplying the time separation between the interfaces by the speed of light within the snow pack. Details of the snow depth retrieval process are provided in Sect. 4. Given the $4.5 \mathrm{GHz}$ bandwidth, the theoretical free-space vertical range resolution is approximately $5 \mathrm{~cm}$. For detection of the snow layer over sea ice, the vertical range resolution improves to approximately $3 \mathrm{~cm}$ due to speed of light variations in the snow pack. However, during post-processing, the data are Hanning windowed to reduce range sidelobes, thus degrading the vertical range resolution by a factor of 2 . At the nominal flight altitude $(460 \mathrm{~m})$ the radar has a footprint size of $11 \mathrm{~m}$ across track (dictated by the pulse-limited footprint 
size) and $14.5 \mathrm{~m}$ along track (dictated by the synthetic aperture formed). The footprint size reduces to the diameter of the first Fresnel zone of $\sim 8 \mathrm{~m}$ when coherent (specular) returns dominate the receive signal. For specular returns to occur, the Rayleigh criterion must be satisfied over the first two Fresnel zones of the radar active area (Carsey, 1992). The Rayleigh criterion is defined as surface roughness $<\frac{\lambda}{8}$, where $\lambda$ is the radar wavelength. For the snow radar, the Rayleigh criterion is satisfied for surface roughness values less than $\sim 1 \mathrm{~cm}$. Such smooth ice is expected to be only rarely encountered over the snow-covered sea ice portions of the survey areas and thus diffuse rather than specular reflections dominate the returns by the radar. Therefore, we take the synthetic aperture dictated footprint size to be the size of the radar active area for our snow depth retrievals.

\subsection{Visible imagery}

We use two sets of aerial photography data for identifying morphological features on the sea ice in conjunction with the radar and laser altimetry data. The use of the aerial photography data was found to be essential to distinguish surface types, which is needed for our sea ice freeboard retrieval process. This also required knowledge of the geolocation of each pixel within the aerial photography data sets. The Digital Mapping System (DMS) (Dominguez, 2009) is available for all flight campaigns after the first Arctic campaign in 2009. The DMS is a digital camera that takes high resolution $(\sim 10 \mathrm{~cm})$ natural color (RGB) photographs that span the length of each IceBridge flight line. The angular resolution of the system is sufficient to cover the full scan width of the laser altimeter measurements. The data are geolocated and the latitude and longitude of each image pixel were determined using metadata parameters provided in each image file.

For the 2009 IceBridge Arctic campaign, the DMS instrument was not available, however, the CAMBOT (Continuous Airborne Mapping By Optical Translator) imaging system was available (Krabill, 2009b). The CAMBOT images are taken once every five seconds along each flight path using a Canon EOS Digital Rebel XTi camera. For the 2009 campaign, the CAMBOT images were not overlapping and there is $\sim 300 \mathrm{~m}$ of track that is not covered between each image. The images are time tagged and the geolocation of the center point, height of the aircraft above the surface, and aircraft heading are provided from the aircraft trajectory information based on the time tag. The angular dimensions of the CAMBOT images for the 2009 Arctic campaign are $58.12^{\circ} \times 40.71^{\circ}$. The aircraft altitude and angular dimensions were used to determine the pixel size for each CAMBOT image in the 2009 data set. The pixel size was combined with the image center point location, aircraft heading, and a standard coordinate rotation to geolocate the pixels of each CAMBOT image. However, the time-tagging procedure for the CAMBOT data set was typically found to be valid only

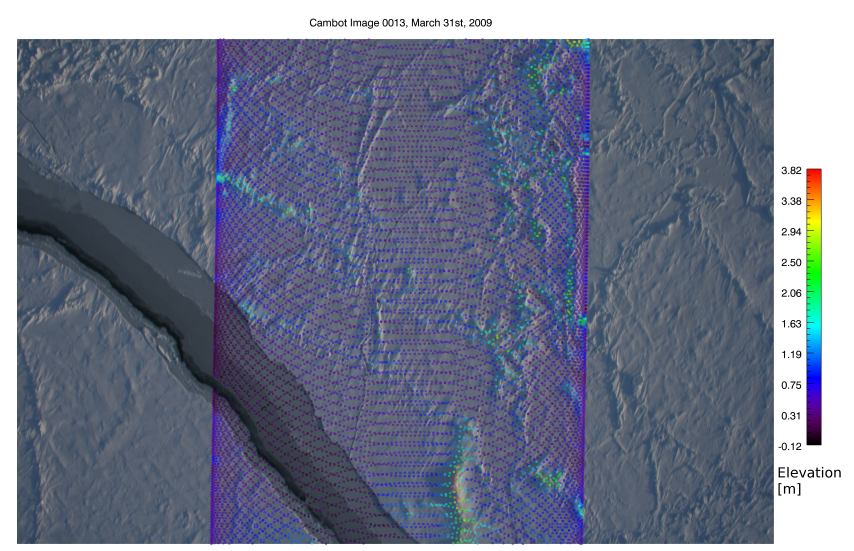

Fig. 4. Example of a CAMBOT image of sea ice with ATM elevation $\left(h_{\text {corr }}\right)$ measurements (colored circles) manually overlain so that features and elevations correspond.

to within \pm 1 second, which introduces geolocation errors for each image. To refine the geolocation of each image, we have designed software to manually align each CAMBOT image. The software overlays the more accurately geolocated ATM elevation data onto each image, and then allows the operator to adjust the CAMBOT geolocation by manually changing the geolocation of the center point of each image. This was done until topographic features such as ridges and leads coincided in both the images and the ATM data. Figure 4 shows an example image of a manually aligned CAMBOT image with ATM data overlain.

\section{Sea ice freeboard retrievals}

Various methods for the retrieval of freeboard from the ATM airborne laser altimetry data have been described in the literature (e.g., Kurtz et al., 2008; Connor et al., 2009, 2012; Kwok et al., 2012). Here, we describe a new approach utilizing geolocated aerial photography and a lead discrimination algorithm to maximize the quality and number of laser altimeter data points used to determine the sea surface height. We have found this to be an important component of the freeboard retrieval step due to the loss of a large percentage of the laser altimeter returns over thin ice-covered and open-water leads (subsequent IceBridge campaigns have utilized a second 3-degree off-nadir ATM laser system, which minimized the loss of laser returns from leads). This loss of data occurs due to specular reflection of the laser pulse away from the receiver when insufficient surface roughness elements are present to cause diffuse scattering. There is still a sufficient number of returns available over leads to determine sea surface height, but this loss introduces two problems: (1) the low (and variable) number of returns over leads compared to the large number of returns from the surrounding sea ice make the returns from leads difficult to uniquely distinguish 
in surface elevation histograms. (2) The loss of laser altimetry data over thin sea ice contributes to an undersampling of these regions and thus a biased freeboard result when taking an areal average. To resolve these issues for more accurate retrieval of sea ice freeboard we use a combination of photography and laser altimetry as described in this section.

The primary product given by the ATM laser altimeter is the surface elevation referenced to the WGS84 ellipsoid, $h_{\mathrm{e}}$. However, the more geophysically useful parameter we wish to retrieve from this product is the height of the snow plus ice surface above sea level, termed the freeboard, fb. The conversion of elevation data into sea ice freeboard is accomplished by subtracting out the instantaneous sea surface height $h_{\text {ssh }}$ from each elevation measurement:

$\mathrm{fb}=h_{\mathrm{e}}-h_{\mathrm{ssh}}$.

The instantaneous sea surface height at a given point in space and time can be written as (Chelton et al., 2001)

$h_{\text {ssh }}=h_{\text {geoid }}+h_{\text {tides }}+h_{\text {pressure }}+h_{\text {dynamic }}$,

where $h_{\text {geoid }}$ is the geoid, $h_{\text {tides }}$ is the contribution of tidal

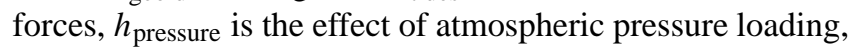
and $h_{\text {dynamic }}$ is the dynamic topography of the ocean surface. We first estimate the sea surface height along the flight tracks using modeled estimates for the $h_{\text {geoid }}, h_{\text {tides }}$, and $h_{\text {pressure }}$ terms. Data sources used in the initial estimation of the sea surface height terms are shown in Table 2. The geoid model is the Earth Gravitational Model 2008 (EGM2008) (Pavlis et al., 2008). The $h_{\text {tides }}$ component can be further decomposed into 4 terms:

$h_{\text {tides }}=h_{\text {ocean }}+h_{\text {load }}+h_{\text {earth }}+h_{\text {pole }}$,

where $h_{\text {ocean }}$ is the ocean tide, $h_{\text {load }}$ is the load tide, $h_{\text {earth }}$ is the solid earth tide, and $h_{\text {pole }}$ is the pole tide. The ATM elevation product is provided in the ITRF standard tide-free system from which the solid earth tide has been removed. A standard latitude dependent correction is also applied to the data used here to place the data in a mean tide system relative to the WGS84 ellipsoid. The pole tide is a small amplitude $(<\sim 2 \mathrm{~cm})$, long wavelength tidal component caused by oscillations in the Earth's rotation axis (Wahr, 1985), it has not been included here since its impact on freeboard determination is negligible (less than $1 \mathrm{~mm}$ of elevation difference over a length scale of $100 \mathrm{~km}$ ). The TPXO6.2 tide model is used to estimate the $h_{\text {ocean }}$ and $h_{\text {load }}$ components (Egbert and Erofeeva, 2002). The isostatic response of the sea surface to atmospheric pressure loading, $h_{\text {pressure }}$, can be rewritten as

$h_{\text {pressure }}=\frac{\Delta P}{\rho_{\mathrm{w}} g}$,

where $\Delta P$ is the difference between the surface air pressure at the local point from the instantaneous mean surface air pressure over the ocean, $\rho_{\mathrm{w}}=1024 \mathrm{~kg} \mathrm{~m}^{-3}$ the density of sea water, and $g=9.8 \mathrm{~m} \mathrm{~s}^{-2}$ the gravitational acceleration (Chelton et al., 2001). In this data set, $\Delta P$ is calculated as the difference between linearly interpolated local surface pressure data provided by the European Center for Medium-Range Weather Forecasts (ECMWF) ERA-Interim data set and an average global mean surface air pressure of $101300 \mathrm{~Pa}$.

As a first step, we remove variations in the instantaneous sea surface height along the flight tracks through the subtraction of modeled estimates for the $h_{\text {geoid }}, h_{\text {tides }}$, and $h_{\text {pressure }}$, resulting in a corrected elevation $h_{\text {corr }}$ :

$h_{\text {corr }}=h_{\mathrm{e}}-\left(h_{\text {tides }}+h_{\text {geoid }}+h_{\text {pressure }}\right)$.

The modeled sea surface height parameters do not at this point have sufficient accuracy for the useful retrieval of freeboard given that a $1 \mathrm{~cm}$ freeboard error corresponds to a $\sim 10 \mathrm{~cm}$ error in sea ice thickness. The periodic identification of local sea surface elevations for use as tie points is required to achieve the desired centimeter level accuracy for freeboard retrievals. After the removal of the modeled sea surface height parameters, the resulting freeboard is calculated as

$\mathrm{fb}=h_{\mathrm{corr}}-z_{\mathrm{ssh}}$,

where $z_{\text {ssh }}$ is the locally determined sea surface elevation with respect to the $h_{\text {corr }}$ elevation data set. The determination of $z_{\text {ssh }}$ at each point along the flight track follows from the retrieval of individual sea surface height observations described in detail below.

A set of sea surface elevation estimates, $h_{\mathrm{tp}}$, are first found through extraction of the $h_{\text {corr }}$ elevation data identified over leads in the IceBridge visible imagery. For all but the Arctic 2009 data set, an automated lead detection algorithm called Sea Ice Lead Detection Algorithm using Minimal Signal (SILDAMS) (Onana et al., 2012) that utilizes the geolocated IceBridge DMS imagery is used. SILDAMS applies a minimal signal transformation on DMS pixel brightness values to carry out a localization around low pixel intensities that correspond to leads. The transformed outputs are within a uniform dynamic variability over the set of numbers from [0, 1] for a variety of input image pixel intensities. This allows specified thresholding of the transformed outputs to be set for the identification and classification of three different lead classes corresponding to open water areas, grease ice/nilas, and newly frozen leads with non-snow-covered grey ice (see Fig. 5). The thresholds are set through manual classification of select lead images within a flight segment and the SILDAMS thresholds are adjusted to optimally match the manually classified ice types. The SILDAMS output for each DMS image is visually examined to ensure the quality of the output, the thresholds are maintained along the flight line until visual examination reveals an error in the output, which occurs at discrete time periods due to camera adjustments to account for changing lighting conditions. Each of these lead 

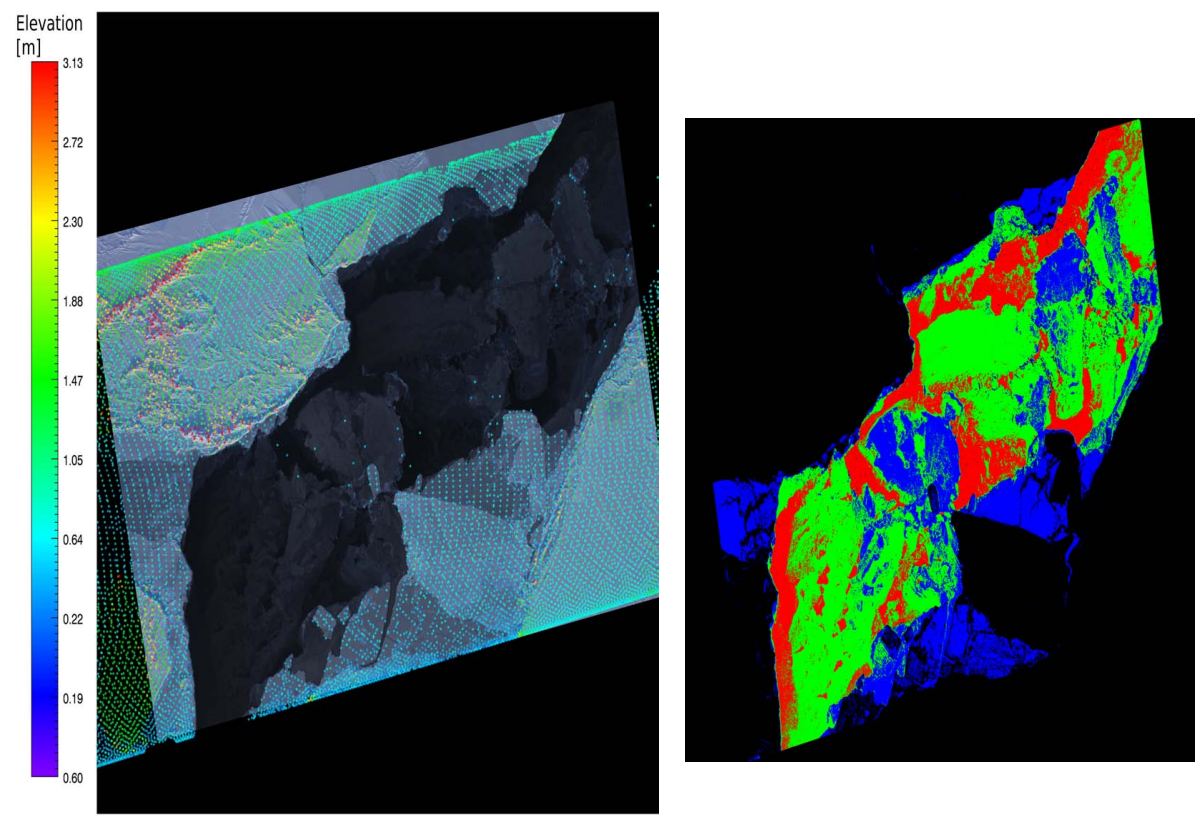

Fig. 5. Example of a DMS image of sea ice with ATM elevation ( $\left.h_{\text {corr }}\right)$ measurements (colored circles) overlain. The right-hand image shows results from the SILDAMS algorithm that is used to distinguish between (1) open water leads (red), (2) nilas and grease ice (green) and (3) non-snow-covered grey-white ice (blue).

Table 3. Summary of radar system parameters impacting the receive signal power and signal-to-noise ratio from the snow-air interface for the 2009 and 2010 campaigns.

\begin{tabular}{lcrr}
\hline Parameter & Symbol in text & 2009 & 2010 \\
\hline Transmit power & $P_{t}$ & $5 \mathrm{~mW}$ & $20 \mathrm{~mW}$ \\
Gain & $\mathrm{G}$ & $10 \mathrm{dBi}$ & $8 \mathrm{dBi}$ \\
Center wavelength & $\lambda$ & $0.063 \mathrm{~m}$ & $0.071 \mathrm{~m}$ \\
Compressed pulse length & $\tau$ & $2.22 \times 10^{-10} \mathrm{~s}^{-1}$ & $2.22 \times 10^{-10} \mathrm{~s}-1$ \\
Time bandwidth-product & $T_{\mathrm{BP}}$ & $60.85 \mathrm{~dB}$ & $60.51 \mathrm{~dB}$ \\
Number of integrations & $N_{l}$ & 16 & 16 \\
System temperature & $T$ & $290 \mathrm{~K}$ & $290 \mathrm{~K}$ \\
System noise figure & $F$ & $21.32 \mathrm{~dB}$ & $19.08 \mathrm{~dB}$ \\
\hline
\end{tabular}

classes has an ice thickness of less than $30 \mathrm{~cm}$ (World Meteorological Organization, 1970) and should thus have an elevation that falls within $3 \mathrm{~cm}$ of the local mean sea level making them suitable for use as sea surface tie points. To account for biases in the use of thin ice areas as sea surface tie points, we subtracted 0.005 and $0.02 \mathrm{~m}$ from the sea surface height estimates derived from the ATM elevation data over grease ice/nilas and grey ice, respectively. These values were chosen to correspond to expected freeboards of snow-free ice types defined in the World Meteorological Organization nomenclature.

For the 2009 Arctic campaign, leads and ice type were categorized through visual inspection of CAMBOT images (Krabill, 2009b). Visual lead identification, rather than an au- tomated approach using SILDAMS, was also used due to the complexity of the CAMBOT images caused by failure of the mechanical camera shutter and uneven exposure in some portions of the images. By matching the location of the leads in the visible imagery with those of the ATM $h_{\text {corr }}$ elevations, the local sea surface elevation and freeboard of each ATM elevation point was retrieved in the same manner as leads identified with SILDAMS. Bias removal due to the use of thin ice types as sea surface tie points was carried out in the same manner as described for the SILDAMS approach. We note that even if leads are present in an area, the number of sea surface elevation estimates may be much more limited in number than those from an equivalent area of returns over 
sea ice due to the loss of ATM data from smooth specularly reflecting surfaces (as can be seen in Figs. 4 and 5).

The spatial size of each individual ATM laser footprint is $1 \mathrm{~m}$ for the nominal flight altitude $(460 \mathrm{~m})$ of the IceBridge data set. To account for geolocation uncertainties $(0.74 \mathrm{~m})$, as well as the presence of mixed lead/sea ice data within the ATM returns, the requirement of a minimum $1 \mathrm{~m}$ lead buffer was set for each ATM return over a lead for it to be used as a sea surface estimate. This is necessary because mixed leadsea ice returns are prevalent due to the highly backscattering sea ice portion of the surface; as such, laser returns near the edge of a lead are not representative of the actual sea surface elevation but rather that of the sea ice within the laser footprint. Thus, the set of sea surface elevation estimates, $h_{\mathrm{tp}}$, are taken from the $h_{\text {corr }}$ elevation data set where leads are identified, and the lead is found to extend an additional $1 \mathrm{~m}$ in all directions beyond the edge of the laser footprint.

Within a given area, the mean sea surface elevation, $\bar{h}_{\mathrm{tp}}$, is derived from the set of sea surface elevation estimates, $h_{\mathrm{tp}}$, that were determined using the combined ATM and visible imagery lead detection method described previously. $\bar{h}_{\mathrm{tp}}$ is calculated using a procedure described in detail below. First, all values of $h_{\mathrm{tp}}$ within $\pm 250 \mathrm{~m}$ from the center point are first combined into a histogram with a $2 \mathrm{~cm}$ bin size to initially determine the local sea surface height. A value of $\pm 250 \mathrm{~m}$ has been chosen to span the width of an individual DMS or CAMBOT image. We expect the local sea surface height to be constant over a length scale corresponding to the first mode baroclinic Rossby radius of deformation, which is on the order of $10 \mathrm{~km}$ for latitudes greater than $60^{\circ}$ and less than $-60^{\circ}$ (Chelton et al., 1998). The Rossby radius is associated with the length scale at which oceanic eddies form; these eddies can cause local inhomogeneities in the sea surface height. The length scale of $\pm 250 \mathrm{~m}$ used for the initial sea surface height determination is much less than the Rossby radius, and thus we expect the actual sea surface height to be constant over this chosen length scale. The standard deviation of the $h_{\mathrm{tp}}$ estimates in this local area is then a measure of the uncertainty of the individual sea surface height estimates due to instrument noise. An analysis of histograms of ATM elevations over known flat surfaces, including separate cases with open water and flat snow-covered sea ice showed that the elevation distributions are Gaussian in shape with a standard deviation of $\sim 10 \mathrm{~cm}$ or less. This has also been observed in separate studies by Farrell et al. (2012) who reported a standard deviation of $5 \mathrm{~cm}$ over a flat, snowcovered refrozen sea ice lead, while Connor et al. (2012) reported a standard deviation of $10 \mathrm{~cm}$ over lead areas. We thus ideally expect the distribution of all $h_{\mathrm{tp}}$ points within the length scale less than the Rossby radius to be similar in shape and width. However, a variety of error sources ranging from laser mounting biases, geolocation errors, misidentification of lead returns in the visible imagery, and errors in the $h_{\text {ssh }}$ data sources lead to deviations from this ideal scenario. These errors also preclude the use of the mean value of the local $h_{\text {tp }}$ observations and standard error analysis techniques from being used to determine $\bar{h}_{\mathrm{tp}}$ and its associated error. The misidentification of lead returns within the combined ATM and photography data causes the largest impact, which, when present, causes the presence of secondary and higher modes in the histogram of $h_{\text {tp }}$ points. In determining $\bar{h}_{\text {tp }}$, we wish to use points corresponding to the mode with the lowest elevation. This is accomplished through the use of the centroid of a Gaussian fit function to the histogram of $h_{\mathrm{tp}}$. The following conditions have been imposed to determine whether the fitted Gaussian function is of high enough quality for use in determining $\bar{h}_{\mathrm{tp}}$ :

$$
\begin{aligned}
& \text { 1. } \sigma_{\text {fit }} \leq 0.11 \mathrm{~m} \text {, } \\
& \text { 2. } \chi^{2}<0.015 \text {, } \\
& \text { 3. } N \geq 40,
\end{aligned}
$$

where $\sigma_{\text {fit }}$ is the standard deviation of the Gaussian fit, $\chi^{2}$ is the reduced chi-square goodness-of-fit, and $\mathrm{N}$ is the number of $h_{\text {tp }}$ points used to construct the histogram for the Gaussian fit. In cases where a multi-modal distribution of $h_{\mathrm{tp}}$ is observed, the above parameters will not be satisfied for the initial Gaussian fit. If this occurs, an iteration is then performed by discarding the largest $h_{\text {tp }}$ elevation point in the set, performing another Gaussian fit, and retesting the fit parameters. The iteration is repeated until the conditions for the fit parameters are satisfied, at which point $\bar{h}_{\mathrm{tp}}$ is determined. If the conditions for the fit parameters are not met, then the sea surface height and freeboard are not calculated. See Fig. 6a for an example of a case where the initial Gaussian fit parameters were satisfied on the first iteration, and Fig. $6 \mathrm{~b}$ for an example case of a multi-modal distribution where the iteration produced a fit of the first mode only.

This procedure produces a set of discrete sea surface height observations (or tie points) along the flight track, Fig. 7 maps the locations of these sea surface height observations for the Arctic campaigns. The availability of these sea surface height observations is non-uniform along each flight track due to ice conditions and dynamics. In particular, few leads were found to occur in the compact multi-year ice areas of the Arctic. This creates uncertainties in the retrieval of freeboard since the accuracy of the sea surface height observations decreases with distance due to remaining uncertainties in the removal of the modeled sea surface height parameters shown in Eq. 2. Therefore, to construct the along-track freeboard profiles and determine the uncertainty of each freeboard estimate (which is inherently variable along the flight path due to uneven lead spacing), the sea surface height along the full flight track was interpolated using an ordinary kriging approach (Cressie, 1993). Although the basin-scale sea surface height field is non-isotropic and non-homogeneous (due to variability in the components of Eq. 2), we assume that the covariance of the sea surface height field is a homogeneous function of distance. The interpolation is then 
a)

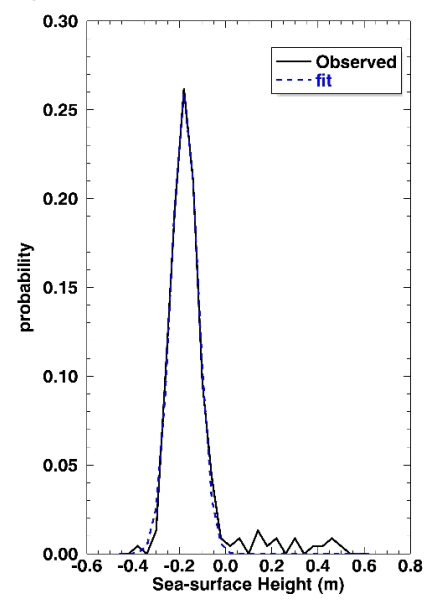

b)

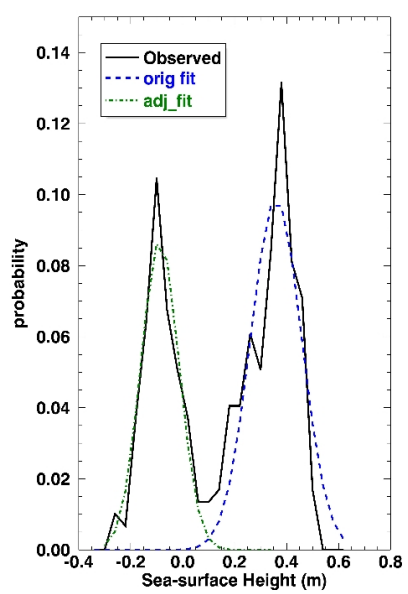

Fig. 6. Histogram of ATM elevations ( $h_{\text {corr }}$ ) over lead areas identified using the SILDAMS algorithm. The Gaussian fits used to determine the instantaneous sea surface height are also shown for two cases: (a) a Gaussian fit which satisfied the fit criteria on the first iteration, and (b) a Gaussian fit which satisfied the fit criteria after the iteration procedure was completed.

performed by minimizing the error variance of the interpolated column vector of sea surface heights for all tie points within $\pm 200 \mathrm{~km}$ of each observation point along the flight path. Briefly, $z_{\text {ssh }}$ is calculated at a given point as

$z_{\mathrm{ssh}}=\mathbf{W}^{\mathbf{T}} \mathbf{z}_{o}$

where $z_{\text {ssh }}$ is the interpolated sea surface height at a specific point along the flight path, $\mathbf{z}_{o}$ is the column vector of sea surface height observations (comprised of the set of $\bar{h}_{\mathrm{tp}}$ values calculated for each flight segment), and $\mathbf{W}$ is the weight column vector. $\mathbf{W}$ is given by

$\left(\begin{array}{c}W_{1} \\ \vdots \\ W_{n} \\ \mu\end{array}\right)=\left(\begin{array}{rrr} & & 1 \\ & \mathbf{C} & \vdots \\ & & 1 \\ 1 & \ldots & 1\end{array}\right)^{-1}\left(\begin{array}{c}C_{o 1} \\ \vdots \\ C_{o n} \\ 1\end{array}\right)$,

$\boldsymbol{W}=\left(\begin{array}{c}W_{1} \\ \vdots \\ W_{n}\end{array}\right)$,

where $\mathbf{C}$ is the covariance matrix and $C_{o y}$ is the covariance between the interpolation point $y$ and the observation point $o$, and $\mu$ is a Lagrange multiplier. The elements of the covariance matrix are assumed to be a homogeneous function of distance, which is modeled as a Gaussian process with the respective elements taken to be

$C_{x y}=\epsilon_{\mathrm{ssh}}^{2}+\sigma_{z}^{2}\left(1-e^{-\frac{d_{x y}^{2}}{L^{2}}}\right)$,

where $d_{x y}$ is the distance between points $x$ and $y, L$ is the correlation length of the sea surface height observations $\left(z_{0}\right)$ along the flight segment (determined from the location where the autocorrelation sequence falls below $e^{-1}$ for each flight), $\sigma_{z}$ is the standard deviation of the sea surface height observations for the flight, and $\epsilon_{\text {ssh }}$ is the uncertainty of the local sea surface height observations. From the previously described method for determining $\bar{h}_{\text {tp }}$ containing at least 40 observations and a standard deviation of $0.11 \mathrm{~m}$, the uncertainty for the sea surface height observations, $\epsilon_{\mathrm{ssh}}$, should theoretically be better than $0.11 / \sqrt{40}=0.017 \mathrm{~m}$. However, additional errors such as unresolved aircraft pitch and roll errors will likely make this number higher since each sea surface height elevation data point, $h_{\mathrm{tp}}$, is not statistically independent. We assume that each of the $\bar{h}_{\text {tp }}$ observations are statistically independent and thus take $\epsilon_{\mathrm{ssh}}=0.058 /\left(\sum_{i=1}^{n} \exp \left(-\frac{d_{o i}^{2}}{L^{2}}\right)\right)^{.5} \mathrm{me}-$ ters (with a maximum value of $\epsilon_{\mathrm{ssh}}=0.058 \mathrm{~m}$ ) based on observations from the 2009 Arctic data set where $0.058 \mathrm{~m}$ is the standard deviation of the differences of all $\bar{h}_{\mathrm{tp}}$ measurements within $\pm 5 \mathrm{~km}$ (the Rossby radius where we expect the sea surface height to be constant) of each individually observed lead. Using a length scale smaller than $\pm 5 \mathrm{~km}$ did not change the maximum value of $\epsilon_{\mathrm{ssh}}=0.058 \mathrm{~m}$ suggesting that this is the minimum uncertainty of a single sea surface height observation due to instrumental limitations. Lastly, the sea ice freeboard is then determined by combining Eqs. 3 and 4. The uncertainty in sea surface height and therefore freeboard at each point is given by

$\sigma_{\mathrm{ssh}}=\left[\left(\begin{array}{llll}W_{1} & \cdots & W_{n} \mu & \mu\end{array}\right)\left(\begin{array}{c}C_{o 1} \\ \vdots \\ C_{o n} \\ 1\end{array}\right)\right]^{\frac{1}{2}}$.

Qualitatively, the local sea surface height is determined by weighting the sea surface height observations as a function of distance, with nearby $\bar{h}_{\text {tp }}$ points receiving the largest weight. The uncertainty decreases as the number of sea surface observations increases and the distance from each sea surface observation decreases, approaching $\sigma_{\mathrm{ssh}}=\frac{0.058}{\sqrt{N}} \mathrm{~m}$ in an area with multiple sea surface height observations. The uncertainty approaches that of the background sea surface height field standard deviation, $\sigma_{z}$, as the distance from the nearest sea surface height observation becomes large.

This method is used to calculate the freeboard and its associated uncertainty at each individual ATM data point $(\sim 1 \mathrm{~m}$ spatial resolution ) where the local sea surface height is determined. However, in order to combine the freeboard data with the snow depth estimates (described in the next section) for the retrieval of sea ice thickness, we place the high resolution freeboard estimates onto the same spatial resolution as the snow depth measurements. This is done by averaging the individual freeboard data to a $40 \mathrm{~m}$ resolution profile along the flight track centered at the snow radar footprints. 
However, due to the loss of ATM data over surfaces with low backscatter (leads and non-snow covered thin ice, such as those examples illustrated in Figs. 4 and 5), an adjustment to the profile data is required to account for the undersampling of the freeboard of thin ice. This adjustment is performed by filling ATM data gaps using the SILDAMS output as a proxy freeboard data set. The freeboard of points corresponding to open water, $f_{\mathrm{ow}}$, were set to zero. The mean freeboard of points corresponding to "thin ice" in the SILDAMS algorithm were set to be $f_{\mathrm{ti}}=0.005 \mathrm{~m}$ corresponding to the WMO freeboard (and ice thickness) for grease ice/nilas. Similarly, points corresponding to the "grey ice" classification in the SILDAMS algorithm were set to be $f_{\mathrm{gi}}=0.02 \mathrm{~m}$. Based on these estimates, we determine an adjusted average freeboard through the combined use of the ATM and SILDAMS freeboard outputs over a $40 \mathrm{~m}$ area. The ATM and SILDAMS data were placed on a $1 \mathrm{~m}$ resolution grid. The $40 \mathrm{~m}$ resolution adjusted freeboard, $\mathrm{fb}_{\mathrm{adj}}$, was found using the following relation:

$\mathrm{fb}_{\mathrm{adj}}=\frac{\left(n_{\mathrm{ow}} f_{\mathrm{ow}}+n_{\mathrm{ti}} f_{\mathrm{ti}}+n_{\mathrm{gi}} f_{\mathrm{gi}}+n_{\mathrm{ice}} \overline{f b}\right)}{\left(n_{\mathrm{ow}}+n_{\mathrm{ti}}+n_{\mathrm{gi}}+n_{\mathrm{ice}}\right)}$,

where $n_{x}$ corresponds to the number of open water, thin ice, grey ice, and sea ice grid points in the $40 \mathrm{~m}$ area detected by SILDAMS, and $\overline{\mathrm{fb}}$ is the mean freeboard from the ATM data within the area. This adjusted freeboard represents the profile of the mean freeboard along the IceBridge flight line where data gaps over low backscattering ice and water surfaces have been taken into account.

The methodology applied for the retrieval of freeboard is independent of location and thus is used to retrieve freeboard for both the Arctic and Antarctic IceBridge campaigns. However, for the 2009 Arctic campaign no DMS data were available for the automated identification of leads. CAMBOT data are available for all of the 2009 Arctic campaign with the exception of $\sim 3 / 4$ of the April 5th flight where mechanical problems prevented photographs from being taken. Thus, it was possible to retrieve freeboard for the 2009 Arctic campaign, but estimates could only be processed to the fib level, rather than to $\mathrm{fb}_{\mathrm{adj}}$.

\section{Snow depth retrievals}

Methods for the retrieval of snow depth from FMCW radar operation over sea ice have been described in previous studies (e.g., Galin et al., 2011; Kwok et al., 2011). Retrieval methods for the IceBridge snow radar have been described by Kurtz and Farrell (2011), and Farrell et al. (2012). The method of Kurtz and Farrell (2011) is used to retrieve snow depth for the 2009 IceBridge campaign in this study. This method also forms the basis of a new method described in this study for the 2010 and future Arctic IceBridge campaigns. We note that the snow depth retrieval method described in this document may be applicable only for the Arc- tic region. For Antarctic sea ice, observations have shown that due to the complicated snow morphology that is often found (Massom et al., 2001), the strongest return in a radar signal may be reflected from an undetermined point within the snow layer rather than the snow-ice interface (Giles et al., 2008b; Willatt et al., 2010) . The presence of flooded sea ice will also complicate the retrieval of snow depth from the radar system. Therefore, we consider the retrieval of snow depth from the snow radar system for the Antarctic region to be a research area that requires in-depth study to understand the results and determine the associated uncertainties.

Briefly, the retrieval algorithms for the snow radar system detect the snow-air and snow-ice interfaces within the radar waveform and determine the snow depth by multiplying the time separation between the interfaces by the speed of light within the snow pack. Comparison of the radar signal with the in situ observations of Farrell et al. (2012) have shown that the strongest peak in the return is expected to correspond to the snow-ice interface, but that the snow-air interface does not often correspond to a distinct peak as may be expected from theoretical arguments. Factors such as instrument noise and response, volume scattering, snow density variations, and surface roughness features all combine to create a complex signal that deviates from the ideal theoretical signal where two distinct peaks are expected to correspond to the snow-air and snow-ice interfaces. Therefore, the method used here to detect the air-snow interface is empirical, but has been shown to produce accurate results in comparison to in situ data (Farrell et al., 2012).

Modifications to the radar hardware and installation between IceBridge campaigns preclude the use of the snow depth retrieval algorithm for the 2009 campaign from being applied to the 2010 and future IceBridge campaigns. For the 2009 campaign, the sub-optimal transmit/receive antenna isolation required reducing the transmit power and attenuating the receiver front end to avoid saturation. Both measures resulted in decreased loop sensitivity. This was evident in the 2009 data as the detected snow-air interfaces were near the noise floor, and the snow depth retrieval algorithm of Kurtz and Farrell (2011) was specifically designed to work under these conditions. In 2010, the radar was rebuilt and the operating frequencies were changed from 2.5-7 to 2.06.5 GHz. By improving the transmit/receive antenna isolation (approximately $35 \mathrm{~dB}$ in 2009 to better than $45 \mathrm{~dB}$ in 2010), the transmit power was increased from $5 \mathrm{~mW}$ in 2009 to $20 \mathrm{~mW}$ in 2010 and the front-end receiver attenuation was reduced thus improving the receiver noise figure and reducing the thermal noise level. Table 3 shows the differences between the radar system parameters for the 2009 and 2010 campaigns. The radar equation for a pulse-limited altimeter (Raney, 1998) outlines the basic set of parameters that influence the received power from the snow-air interface:

$P_{\mathrm{r}}=\frac{P_{\mathrm{t}} G^{2} \lambda^{2} \sigma^{0} \pi c \tau T_{\mathrm{BP}}}{(4 \pi R)^{3}}$ 

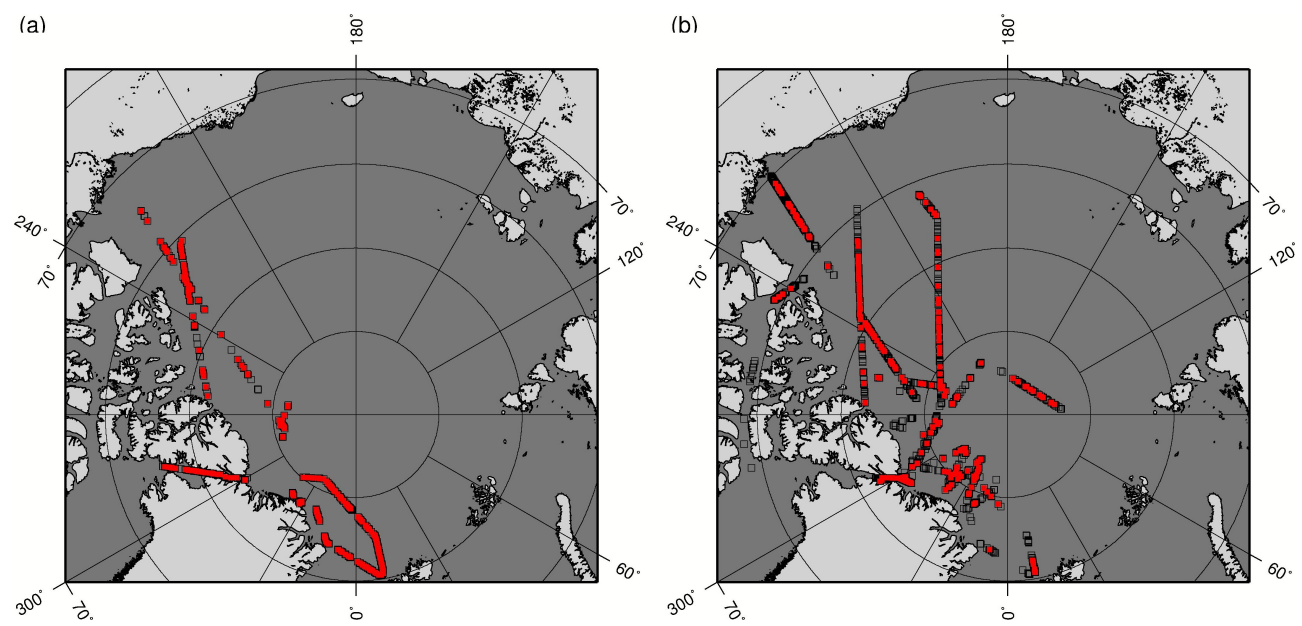

Fig. 7. Map of lead locations identified in the aerial photography data sets for (a) 2009 and (b) 2010. Black boxes represent areas where leads were identified in the aerial photography and the red points represent leads which contained sufficient ATM measurements suitable for the retrieval of the instantaneous sea surface height.

Table 4. Summary of all uncertainty components propagated in the calculation of the final IceBridge sea ice thickness uncertainty.

\begin{tabular}{lccl}
\hline Parameter & Symbol in text & Uncertainty & Source \\
\hline Snow density & $\sigma_{\rho_{s}}$ & $100 \frac{\mathrm{kg}}{\mathrm{m}^{3}}$ & Climatological variability \\
Sea ice density & $\sigma_{\rho_{i}}$ & $10 \frac{\mathrm{kg}}{\mathrm{m}^{3}}$ & Estimated variability from in situ measurements \\
Snow depth & $\sigma_{h_{s}}$ & $0.057 \mathrm{~m}$ & Estimate from in situ comparison \\
Freeboard & $\sigma_{h_{f}}$ & Variable $(\sim 1 \mathrm{~cm}$ to $30 \mathrm{~cm})$ & Kriging error (see Sect. 3) \\
\hline
\end{tabular}

Table 5. Mean freeboard, snow depth, and sea ice thickness for the 2009-2010 IceBridge flights. The flight numbers correspond to the flight lines mapped in Fig. 2. The mean freeboard and thickness values are reported only using data where the freeboard uncertainty is $\leq 0.1 \mathrm{~m}$, the mean ice thickness uncertainty is in parentheses. The mean snow depth is reported for the entire flight track where snow depth is $>0.05 \mathrm{~m}$ and less than the derived freeboard.

\begin{tabular}{lcccc}
\hline $\begin{array}{l}\text { Flight } \\
\text { date }\end{array}$ & $\begin{array}{c}\text { Flight } \\
\text { number }\end{array}$ & $\begin{array}{c}\text { Mean } \\
\text { freeboard [m] }\end{array}$ & $\begin{array}{c}\text { Mean snow } \\
\text { depth [m] }\end{array}$ & $\begin{array}{c}\text { Mean sea ice } \\
\text { thickness [m] }\end{array}$ \\
\hline $3 / 31 / 2009$ & 1 & 0.42 & - & - \\
$4 / 2 / 2009$ & 2 & 0.48 & 0.31 & $2.50(0.74)$ \\
$4 / 5 / 2009$ & 3 & 0.45 & 0.21 & $2.54(0.65)$ \\
$4 / 21 / 2009$ & 4 & 0.67 & 0.38 & $3.82(0.75)$ \\
$4 / 25 / 2009$ & 5 & 0.51 & 0.28 & $3.71(0.66)$ \\
$10 / 30 / 2009$ & 6 & 0.59 & - & - \\
$3 / 23 / 2010$ & 7 & 0.52 & 0.34 & $3.39(0.78)$ \\
$3 / 26 / 2010$ & 8 & 0.32 & 0.26 & $2.91(0.67)$ \\
$4 / 2 / 2010$ & 9 & 0.18 & 0.15 & $1.77(0.64)$ \\
$4 / 5 / 2010$ & 10 & 0.51 & 0.24 & $3.64(0.64)$ \\
$4 / 12 / 2010$ & 11 & 0.53 & 0.29 & $3.62(0.68)$ \\
$4 / 19 / 2010$ & 12 & 0.38 & 0.23 & $2.58(0.58)$ \\
$4 / 20 / 2010$ & 13 & 0.48 & 0.26 & $3.22(0.72)$ \\
$4 / 21 / 2010$ & 14 & 0.43 & 0.25 & $3.00(0.59)$ \\
\hline
\end{tabular}

where $P_{\mathrm{r}}$ is the received power, $P_{t}$ is the transmit power, $G$ is the antenna gain, $\lambda$ the wavelength, $\sigma^{0}$ the backscattering coefficient, $\tau$ is the compressed pulse length (equal to the reciprocal of the radar bandwidth), $T_{\mathrm{BP}}$ is the range time bandwidth product, and $R$ is the range to the target. The signalto-noise ratio (SNR) is given by

$\mathrm{SNR}=\frac{P_{t} G^{2} \lambda^{2} \sigma^{0} \pi c \tau T_{\mathrm{BP}} N_{I}}{(4 \pi R)^{3} k T B F}$,

where $N_{I}$ is the number of coherent integrations, $k$ is the Boltzmann constant, $T$ is the system temperature, $B$ is the bandwidth, and $F$ is the system noise figure. To demonstrate the improved SNR between the two campaigns, we use Eq. 7 and take a ratio for the two campaigns (assuming a constant backscattering coefficient, flight altitude, center wavelength, and the values shown in Table 3) that yields an increased SNR of $\sim 4.9 \mathrm{~dB}$ for the received signal from the snow-air interface for the 2010 campaign. The $\sim 4.9 \mathrm{~dB}$ improvement in SNR can be primarily attributed to the increase in transmit power.

The improved radar design and subsequent increased signal-to-noise ratio for the 2010 data and future data sets means that modifications to the snow depth retrieval algorithm of Kurtz and Farrell (2011) are required. To account for these changes in the radar configuration, in the 2010 
campaign we base the detection thresholds for the air-snow interface on the relative radar return power. We use the 2009 radar data set as the basis for the algorithm changes since the in situ study of Farrell et al. (2012) demonstrated the successful detection of the snow-air interface by the algorithm, and thus provides us with a reference data set of the return power values from the snow-air and snow-ice interfaces. The location of the snow-ice interface is still defined as the largest maxima in the radar signal below the airsnow interface. The return power in $\mathrm{dB}$ is calculated here as $P=10 \times \log _{10}\left(\frac{m_{\text {data }}}{N_{\text {echo }}}\right)$ where $m_{\text {data }}$ is the magnitude of the echogram data and $N_{\text {echo }}$ is the number of points in an individual radar waveform. To improve the SNR and reduce the possibility of radar speckle from being misidentified as an interface layer, the return power data were first incoherently averaged (incoherent averaging rather than coherent averaging is done since phase information was not originally provided in the 2009 data set) over 40 points corresponding to a length scale of $\sim 40 \mathrm{~m}$. The return power values for the snow-air interfaces identified in the 2009 data set were found to vary between $P_{s-a}^{\min }=-4.0 \mathrm{~dB}$ and $P_{s-a}^{\max }=-0.5 \mathrm{~dB}$, with a mean value of $P_{s-a}^{\text {mean }}=-2.35 \mathrm{~dB}$, and these same conditions are used to locate the snow-air interfaces in the 2010 data set. However, the data from the snow radar are presently not radiometrically calibrated and thus vary based on the parameters of the instrumentation, the flight parameters (Eq. 6), and the processing methodologies used to create the final data values. Thus, the return power values for the 2010 IceBridge campaign are not directly equivalent to those from the 2009 data set.

Given the differences between the radar system in 2009 and 2010, differences due to flight operation considerations (such as altitude), and lack of radiometric calibration for the return power values, a calibration adjustment for each individual radar echogram is therefore necessary to determine the final threshold power range where we expect the snowair interface to be located. First, we define scale, $m$, and offset, $b$, parameters, which are determined for each echogram by simultaneously solving

$y_{1}=m x_{1}+b$,

$y_{2}=m x_{2}+b$,

where $y_{1}=2.25 \mathrm{~dB}$, which is the average power of the snow-ice interface observed in the 2009 Arctic data set, $x_{1}$ is the average power of the snow-ice interface for the desired radar echogram, $y_{2}=-5.0 \mathrm{~dB}$ is the mean noise level, which is defined as the average power of the first 100 bins located at least $5 \mathrm{~m}$ above the point of maximum power (assumed to be in the air above the snow pack) in the 2009 Arctic data set, and $x_{2}$ is the mean noise level, which is similarly defined as the average power of the first 100 bins located at least $5 \mathrm{~m}$ above the point of maximum power for the desired radar echogram. Here we define the maximum power of the adjusted snow-air interface as $\hat{P}_{s-a}^{\max }=m P_{s-a}^{\max }+b$, similarly the minimum power for the adjusted snow-air interface is defined as $\hat{P}_{s-a}^{\min }=m P_{s-a}^{\min }+b$. We use these conditions to determine the region of the radar return where we expect the snow-air interface to be located. The search for the snow-air interface thus occurs when the return power level, $P_{s-a}$, for the snow-air interface satisfies the following requirements:

$P_{s-a} \geq \hat{P}_{s-a}^{\min }$,

$\overline{P_{s-a}} \geq \hat{P}_{s-a}^{\min }$,

where $\overline{P_{s-a}}$ is the mean power in the six range bins that follow the first point with power $\geq \hat{P}_{s-a}^{\min }$. These conditions identify the beginning portion of the return from the snow-air interface by finding the point where the minimum expected return power from the interface is reached (first condition) and when volume scattering from within the snow pack is also present (second condition). Once these conditions are satisfied the snow-air interface is defined following the observations described in Farrell et al. (2012) to be either the location of the first local maxima in the return or the point of continuous power increase. The snow-air interface is thus defined here as the first point where one of the following conditions is satisfied:

1. The point of continuous power increase of the radar return from the snow-air interface is found. The point of continuous power increase is defined here as the point where the radar return power begins to continuously increase (i.e., $\frac{\partial P_{r}}{\partial x}>0$ ) until the maximum expected snow-air interface power, $\hat{P}_{s-a}^{\max }$ is reached.

2. If a local maxima occurs greater than $m P_{s-a}^{\text {mean }}+b$ and $\sigma$ above the adjacent points (to eliminate random noise from being misidentified as a maxima), where $\sigma$ is the standard deviation of the radar noise level, then this point is chosen as the snow-air interface location.

Examples of two radar waveforms from the 2010 data set illustrating cases where a distinct local maxima is not found (condition 1) and is found (condition 2) are shown in Fig. 8. The figure shows that the theoretical case of an easily distinguishable maxima corresponding to a reflection from the snow-air interface is not observed in the data. Thus, the power range between $\hat{P}_{s-a}^{\min }$ and $\hat{P}_{s-a}^{\max }$ is used to identify the distinct region in the return waveform where the snow-air interface is located.

An iteration of the above method is performed when the difference between the echogram mean noise level and the echogram mean snow-ice interface power is greater than twice the mean difference observed in the 2009 campaign data set (equal to $14.5 \mathrm{~dB}$ ). The iteration is performed by 




Fig. 8. (a) Example of calculated snow-air (red line) and snow-ice (black line) interfaces for a radar file from the 2010 data set. (b) Example radar waveform illustrating the range of power values where the snow-air interface is located. In this case, the snow-air interface corresponds to the first point of continuously increasing power rather than a distinct peak. The snow-ice interface is the point of maximum power. (c) Example radar waveform illustrating the case where a distinct peak is found for the snow-air interface.

rescaling the threshold power values: $y_{1}$ is set equal to the mean echogram power for the initially determined snow-air interface and $y_{2}=P_{s-a}^{\text {mean }}$. The initial scaling provides an approximation for the parameters $m$ and $b$ by scaling the return power values by the snow-ice interface power and the system noise, however as previously demonstrated, changes to the snow radar system have reduced the noise level in successive campaigns so the initial scaling is only an approximation. The iteration scales the return power values to the snow-air interface allowing for more accurate estimates of $m$ and $b$ to be made when there is a large difference between the mean noise level and snow-ice interface power.

The snow depth is then found by calculating the delay time between the snow-air and snow-ice interfaces and multiplying this difference by the speed of light within the snow pack, $c_{\text {snow }}$. The speed of light in the snow pack was taken to follow the relation between dry snow density and dielectric constant given by Tiuri et al. (1984) as

$\epsilon_{d}=1+2 \rho_{s}$,

$c_{\text {snow }}=\frac{c}{\sqrt{\epsilon_{d}}}$, where $c$ is the speed of light in vacuum and $\rho_{s}$ is the snow density (in $\frac{\mathrm{g}}{\mathrm{cm}^{3}}$ ). The snow density was taken to be $320 \frac{\mathrm{kg}}{\mathrm{m}^{3}}$ following the climatological mean snow density provided in Warren et al. (1999). Once the snow-air and snow-ice interfaces are identified, we apply a locally weighted robust linear regression at a $40 \mathrm{~m}$ length scale to reduce the impact of outliers in the final determination of the snow-air and snow-ice interface locations. This effectively reduces the spatial resolution of the retrieved snow depths to $40 \mathrm{~m}$.

As described in Kurtz and Farrell (2011), the behavior of the radar over leads and the apex of steep pressure ridges must also be accounted for in the snow depth retrieval method. Lead areas were flagged using the method described in Kurtz and Farrell, (2011) and the snow depth is set to zero to correspond to the negligible snow cover on open water and newly frozen leads. We also discard data where the signal is too low for the retrieval of snow depth. Based on the analysis of coincident ATM laser data used to identify locations where there is large disagreement between the laser and radar snow-air interfaces, the conditions for discarding the data due to insufficient signal strength were set as

$P_{s-i} \geq-1.5 m+b[\mathrm{~dB}]$, 


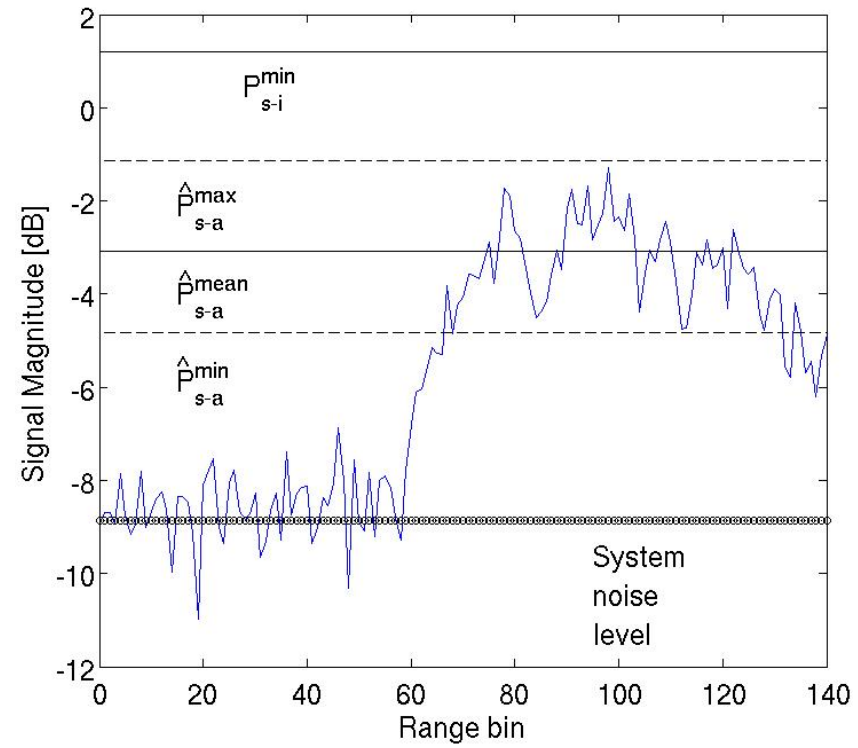

Fig. 9. Example radar waveform over a ridge. The point of maximum power in the radar waveform is within the expected range for the snow-air interface and does not reach the minimum required threshold, $P_{s-i}^{\min }$.

$\overline{P_{s-i}} \geq-1.5 m+b[\mathrm{~dB}]$,

where $\overline{P_{s-i}}$ is the mean power in the three range bins that follow the estimated snow-ice interface, and $m$ and $b$ are found by solving Eqs. 8 and 9. An example radar waveform is shown in Fig. 9 over a sea ice ridge that was identified in the ATM and DMS data sets. This loss of signal typically occurs over the apex of steep pressure ridges, however, comparison with in situ data (Farrell et al., 2012) showed this data loss did not limit the ability of the snow radar to capture the mean snow depth of a region since the snow surrounding the ridges was still retrieved. Additionally, Kurtz and Farrell (2011) demonstrated the difference between the snow radar for the full 2009 data set is within $0.3 \mathrm{~cm}$ of the climatology of Warren et al. (1999) and provides further support that the mean snow depth over a variety of ice types is captured. If the snow depth data set from the snow radar was not representative of the mean snow depth over the full range of ice types it could potentially lead to errors in the retrieval of sea ice thickness. How representative the snow radar data is on basin scale will continue to be examined as future studies with coincident in situ survey lines conducted in 2011 and 2012 are completed. In total, $16 \%$ of the snow depth data was discarded for the 2009 campaign, and $21 \%$ was discarded for the 2010 campaign.

In addition to discarding data due to insufficient signal strength, it is also necessary to filter data that have been negatively impacted by other physical constraints. As shown by Kurtz and Farrell (2011) it is necessary to discard data col- lected with warm surface temperatures due to the presence of liquid water, which changes the dielectric properties of the snow pack. Similar to the study of Kurtz and Farrell (2011), we discard data when the surface temperature is greater than $-5^{\circ} \mathrm{C}$, this is the temperature threshold identified in observations by Barber et al. (1995) where large dielectric changes in the snow pack begin to take place. When available, the surface temperature is determined from the IceBridge KT-19 infrared radiation pyrometer data set (Shetter et al., 2010). When instrumental observations are unavailable, we use the thermodynamic sea ice model of Kurtz et al. (2011) forced with ECMWF meteorological data to determine the surface temperature. Lastly, flight altitude variations also need to be taken into account. The nominal IceBridge flight altitude is $460 \mathrm{~m}$, but is variable due to mission requirements and weather considerations. A maximum altitude of $540 \mathrm{~m}$ for the 2009 campaign and $675 \mathrm{~m}$ for the 2010 campaign is set for the retrieval of snow depth. These altitude limits correspond to the point where the expected snow-air interface return power is near to the system noise level for the respective campaigns given a $1 / R^{3}$ return power dependence.

The method applied for the retrieval of snow depth differs between the 2009 and 2010 seasons. The method applied to the 2009 data set was validated through comparison to in situ data, which gives us a measure of confidence in the snow depths for that season (Farrell et al., 2012), as well as a demonstrated agreement with the climatology of Warren et al. (1999) (Kurtz and Farrell, 2011). However, no in situ surveys were conducted in 2010, which precludes a thorough assessment of the 2010 data set. Multiple overflights of in situ surveys were conducted in subsequent years (as of this writing, in 2011 and 2012), which will allow more detailed analysis of the retrieval methods and associated uncertainties described in this study. To assess the quality of the snow depth retrievals from the 2010 data set we compare the snow-air interface retrieved from the radar to that derived from the ATM surface elevation data. Figure 10 shows an example of a radar echogram from the 2010 data set with the chosen snow-air (red line) and snow-ice interfaces (black line). Also shown is the ATM corrected elevation $\left(h_{\text {corr }}\right)$ data (green line), which should ideally correspond to the snowair interface detected by the radar. However, the radar data are referenced as a relative distance from the snow radar antenna, rather than to a standard geodetic coordinate system such as the WGS84 ellipsoid used for the ATM data. Therefore, we take a mean difference between the ATM elevation (averaged to a $40 \mathrm{~m}$ resolution) and the chosen snow-air interface to construct the plot. The figures show the ability of the tracking algorithm to identify the snow-air interface, and also show the behavior over ridges and thin ice. We used the coincident ATM data to assess the ability of the algorithm to determine the quality of the snow-air interface. A probability distribution showing the correlation between the ATM data and the identified snow-air interface for each snow radar echogram is presented in Fig. 11. The figure illustrates that 

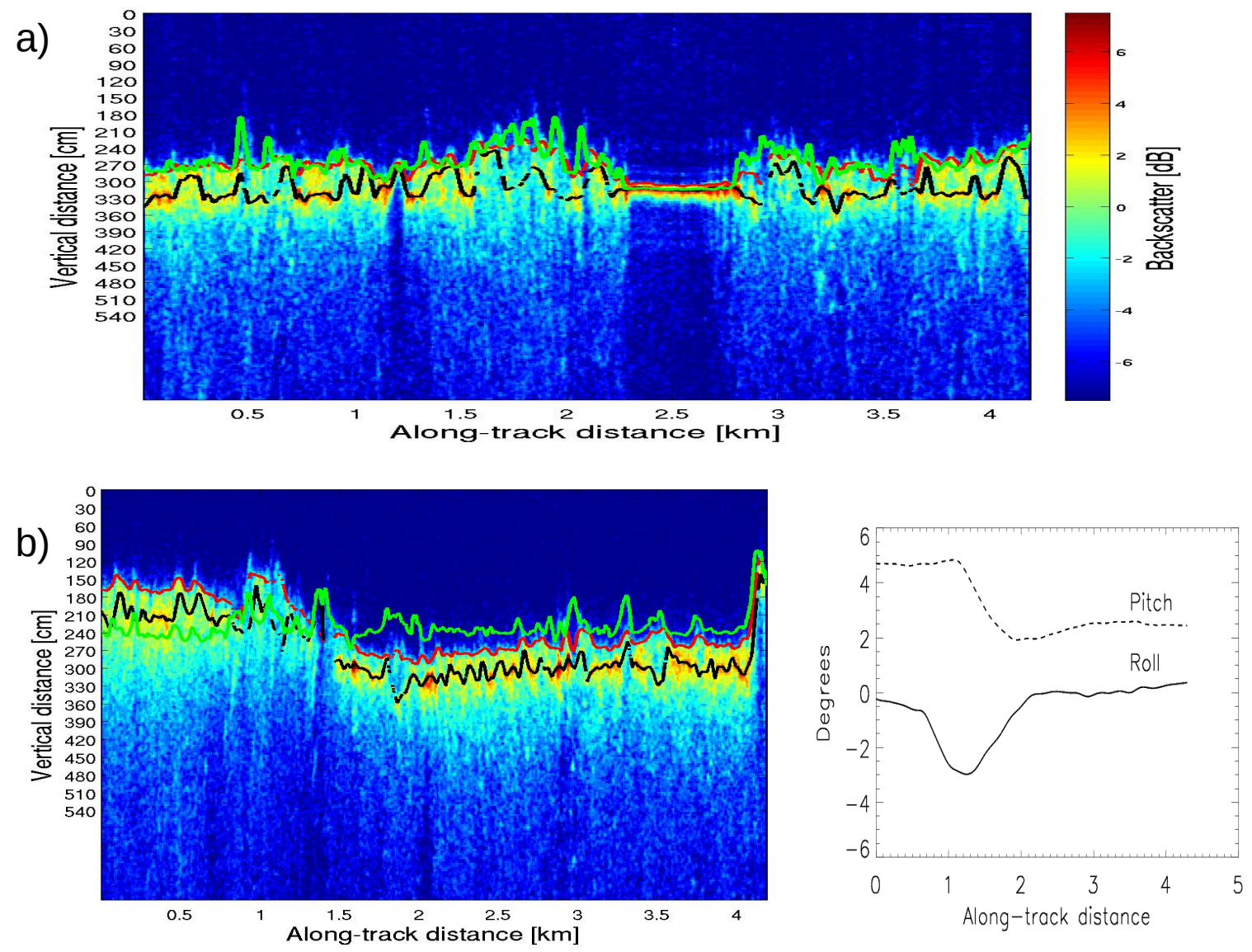

Fig. 10. 2010 IceBridge ATM and snow radar comparison for (a) level flying by the aircraft and (b) non-level flying corresponding to aircraft pitch and roll changes of 3 degrees beginning near the $1 \mathrm{~km}$ along-track distance portion of the flight. The green line is the ATM snow-air surface, the red line is the calculated snow-air interface from the radar data, the black line is the calculated snow-ice interface. The correlation between the ATM and snow radar picked snow-air interface is 0.75 for the level flying case and 0.19 for the non-level flying case.

the correlation is quite variable. The maximum correlation of the ATM and radar data is near 1 with a mode around 0.55 demonstrating the ability of the snow-air interface algorithm to track the snow surface in certain cases. The modal correlation of 0.55 is also similar to the results of Farrell et al. (2012) who observed a maximum correlation of 0.7 when comparing the IceBridge derived snow depths with in situ data.

The observation that many echograms have only moderate to low correlations can be explained due to a combination of uncertainties in the snow depth retrievals (such as due to the finite range resolution of $\sim 5 \mathrm{~cm}$ ), geolocation uncertainties in the snow radar data, and aircraft motion. Low variability of the snow-air interface location can also reduce the correlations as the ATM and radar system noise will dominate in these cases. Additional uncertainties in the radar data comparison arise due to the uncorrected lever arm between the GPS antenna, to which the INS data is referenced to, and the monostatic phase center of the radar. This influences the comparison in two ways: (1) it leads to errors in the vertical range compensation, which are used to account for changes in the aircraft altitude and (2) it introduces a 5-20 m offset between the geolocations of the snow radar and ATM. While we expect that averaging to a $40 \mathrm{~m}$ length scale reduces the problem of geolocation errors of this magnitude for sea ice thickness retrievals using the radar and ATM freeboard data, it nonetheless is a source of error if one seeks to carry out a one-to-one matching of the ATM data over the snow radar footprint such as done by Kwok et al. (2011). Aircraft pitch and roll introduces errors in the aircraft altitude correction that results in residual features in the vertical dimension of the radar data when they are compared to the ATM elevation data that have been corrected for aircraft pitch and roll. Figure 10 shows two example radar echograms where good correlation between the ATM surface elevation and radar retrieved snow-air interface over small length scales can be seen visually, but Fig. 10b demonstrates the impact of uncorrected aircraft motion on the snow radar data, which can be clearly seen when compared to the motion corrected ATM elevation data. The pulse-limited processing and large beamwidth of the antenna $\left(45^{\circ}\right.$ by $\left.45^{\circ}\right)$ will still 


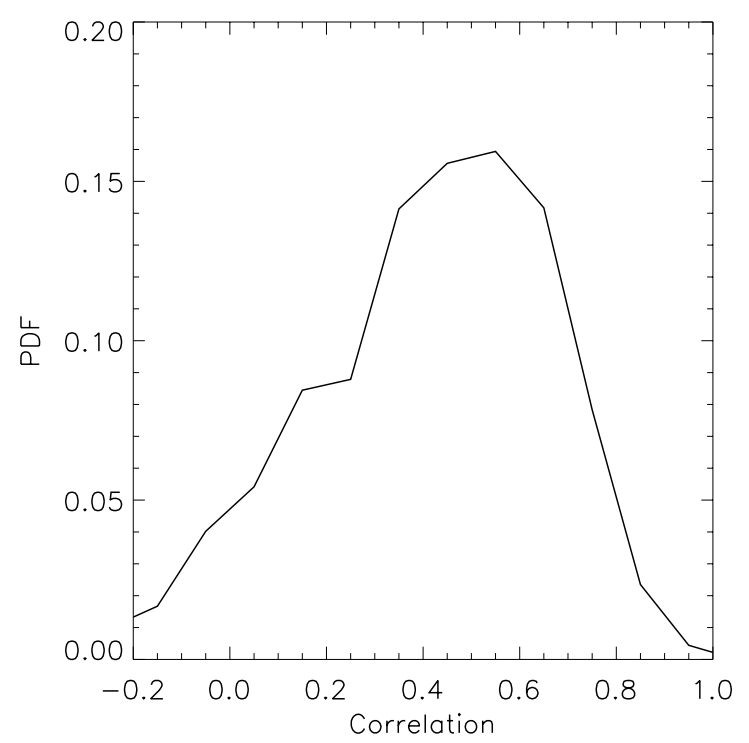

Fig. 11. Probability density function of the correlation between the ATM-derived snow-air interface and the picked radar snow-air interface over each $\sim 4 \mathrm{~km}$ radar echogram for the 2010 Arctic campaign.

produce a return from nadir even when the aircraft is not level (typical flight operating parameters do not have roll angles greater than 20 degrees), however the uncorrected lever arm between the GPS and radar antennas introduces errors in the aircraft altitude correction, which appear as vertical variations (Fig. 10b). Since we define the snow depth as the relative difference between the snow-air and snow-ice interfaces, and the pitch and roll typically does not change significantly over the $40 \mathrm{~m}$ retrieval length scale, we expect that aircraft motion will have little impact on our snow depth retrievals. However, these pitch and roll fluctuations introduce a randomly varying, but continuous source of error in the correlation between the ATM and snow radar snow-air interface locations. For the 2009 Arctic campaign, the standard deviation of aircraft pitch was 0.25 degrees and the standard deviation of roll was 2.6 degrees. Given the magnitude of the pitch and roll variations across the flight lines, we use the correlations with the ATM freeboard data as qualitative evidence that our snow-air tracking algorithm is capable of accurate retrievals under ideal conditions (as evident in the right-hand tail of the correlation histogram shown in Fig. 11). However, the combined ATM-snow radar data set cannot currently be taken as a quantitative assessment of the snow-air interface retrieval quality. Future planned comparisons with in situ data sets are needed to determine a quantitative estimate of the snow depth retrieval quality.

\section{Sea ice thickness retrievals}

\subsection{Thickness determination}

Sea ice thickness, $h_{i}$, is calculated using the corresponding $40 \mathrm{~m}$ scale freeboard and snow depth data sets as input for the hydrostatic balance equation:

$h_{i}=\frac{\rho_{w}}{\rho_{w}-\rho_{i}} \mathrm{fb}_{\mathrm{adj}}-\frac{\rho_{w}-\rho_{s}}{\rho_{w}-\rho_{i}} h_{s}$,

where $\mathrm{fb}_{\mathrm{adj}}$ is the freeboard (described in Sect. 3), $h_{s}$ is the snow depth (described in Sect. 4), $\rho_{w}$ is the density of sea water, $\rho_{i}$ is the density of sea ice, and $\rho_{s}$ is the density of snow. $\rho_{w}$ and $\rho_{i}$ are taken to be $1024 \frac{\mathrm{kg}}{\mathrm{m}^{3}}$ and $915 \frac{\mathrm{kg}}{\mathrm{m}^{3}}$, which are derived from the result of numerous field measurements summarized by Wadhams et al. (1992). $\rho_{s}$ is taken to be 320 $\frac{\mathrm{kg}}{\mathrm{m}^{3}}$ following the climatological values compiled by Warren et al. (1999).

\subsection{Error analysis}

The error in the sea ice thickness retrieval (excluding the negligible contribution of errors due to variations in sea water density) can be written as

$$
\begin{aligned}
& \sigma_{h_{i}}=\left[\left(\frac{\rho_{w}}{\rho_{w}-\rho_{i}}\right)^{2} \sigma_{h_{f}}^{2}+\left(\frac{\rho_{s}-\rho_{w}}{\rho_{w}-\rho_{i}}\right)^{2} \sigma_{h_{s}}^{2}+\right. \\
& \left.\left(\frac{h_{s}\left(\rho_{s}-\rho_{w}\right)+h_{f} \rho_{w}}{\left(\rho_{w}-\rho_{i}\right)^{2}}\right)^{2} \sigma_{\rho_{i}}^{2}+\left(\frac{h_{s}}{\rho_{w}-\rho_{i}}\right)^{2} \sigma_{\rho_{s}}^{2}\right]^{\frac{1}{2}}
\end{aligned}
$$

where $\sigma_{h_{i}}, \sigma_{h_{f}}, \sigma_{h_{s}}, \sigma_{\rho_{s}}$, and $\sigma_{\rho_{i}}$ are the uncertainties of the ice thickness, freeboard, snow depth, and densities of snow and ice, respectively. A summary of the uncertainty terms is provided in Table 4. Density uncertainties are taken from previous in situ measurements described in the literature: $\sigma_{\rho_{s}}$ is estimated to be $100 \mathrm{~kg} \mathrm{~m}^{-3}$ based on the variability of $\rho_{s}$ in the climatology of Warren et al. (1999), $\sigma_{\rho_{i}}$ is estimated here to be $10 \mathrm{~kg} \mathrm{~m}^{-3}$, which represents the expected range of densities for sea ice between 0.3 and $3 \mathrm{~m}$ thick (Kovacs, 1996) as well as the typical range of sea ice densities from observations (Wadhams et al., 1992). We note that the density of sea ice may be dependent on ice type, with the density of multi-year ice typically being lower than that of first year ice due to the presence of air bubbles (Wadhams et al., 1992; Alexandrov et al., 2010). The mean density of sea ice has also been found to be variable with respect to the amount of ice that is above the water line, as well as the sea ice salinity and temperature (Timco and Frederking, 1995; Eicken et al., 1995). The use of a density value that is based on a specific ice type or geographical region will be investigated in future studies. The uncertainty in the freeboard retrieval, $\sigma_{h_{f}}$, is variable along the flight path as described in Sect. 3. The uncertainty in snow depth is not well constrained at the time 
of this writing. Uncertainty in the snow depth occurs due to a variety of factors including the finite range resolution of the radar, density uncertainties, and uncertainty in the detection of the snow-air and snow-ice interfaces. Considering only uncertainties in range resolution and speed of light variations, Kwok et al. (2011) calculated an error of 3.5 to $5 \mathrm{~cm}$ for snow depths between 10 and $70 \mathrm{~cm}$. This represents the minimum expected uncertainty in snow depth derived from the radar. Following the discussion in Sect. 4 on issues involving detection of the snow-air interface, we expect that uncertainties in interface detection will play a much more significant role in the uncertainty of the snow depth retrieval. The combined uncertainties due to speed of light variations and interface detection uncertainties mean that a robust error estimate for an individual snow depth measurement should be derived by computing the standard deviation of differences between coincident radar and in situ data sets. However, spatial offsets between the IceBridge data and in situ measurements described in Farrell et al. (2012) preclude a robust error assessment from being done, and no other coincident in situ survey data exist for the 2009-2010 time period. For the purposes of this study, we estimate the uncertainty using the difference between the IceBridge data and in situ snow depth described in the study by Farrell et al. (2012). The mean difference between the survey and IceBridge data set was $0.8 \mathrm{~cm}$, and there were 50 independent observations ( $40 \mathrm{~m}$ spatial resolution for each radar observation over a $\sim 2 \mathrm{~km}$ survey line). Assuming the IceBridge and in situ data are unbiased, the error is calculated as $\sigma_{h_{s}}=0.8 \times \sqrt{50}=5.7 \mathrm{~cm}$. While this is a simplistic error analysis, it is a useful estimate of the expected uncertainty since it incorporates the important effect of interface detection issues. However, we await further refinement of this uncertainty value through the analysis of multiple coincident in situ data surveys conducted during the 2011 and 2012 campaigns. Improvements to the snow radar and increased signal-to-noise ratio over the 2009 to present time period may also lead to campaign specific uncertainty estimates.

The uncertainty in ice thickness is calculated using Eq. 16, using the uncertainties for each variable described above and in Table 4. The sea ice thickness uncertainty is thus a variable quantity, in particular due to the variable uncertainty in the freeboard retrievals. It is also important to note that the uncertainties in the freeboard are correlated over long length scales due to the procedures for determining the sea surface height, therefore, spatial averaging of the data to reduce the uncertainty will need to take this into account.

We provide an estimate of sea ice thickness over a $40 \mathrm{~m}$ length scale to provide the highest resolution available from the data. However, since sea ice is a rigid body the hydrostatic balance equation does not necessarily apply for each of the $\sim 40 \mathrm{~m}$ resolution freeboard and snow depth measurements taken along the flight path. An analysis of Arctic sea ice by Forsström et al. (2011) found an uncertainty of $0.5 \mathrm{~m}$ associated with non-local hydrostatic balance. Sim- ilarly, Doble et al. (2011) showed that the ice thickness error in the use of the hydrostatic balance equation was $0.4 \mathrm{~m}$ for averaging length scales of $300 \mathrm{~m}$. The dependence of this error on length scale was observed to be dependent on the ice type, the error in level ice decreased faster with increasing averaging length than the error of deformed ice. The use of a $40 \mathrm{~m}$ length scale used here for calculating the sea ice thickness will thus have an additional error term due to local nonhydrostatic balance effects. This error is important to consider when comparing the IceBridge data to small-scale measurements, but will become minimal when averaging over length scales greater than the size of an individual ice floe since the large-scale ice pack is in hydrostatic equilibrium.

\section{Results for 2009 and 2010}

In this section we show the results of the retrieved freeboard, snow depth, and sea ice thickness data for the 2009-2010 IceBridge campaigns. For the purposes of this section we only use data where the uncertainty in the retrieved freeboard is less than $0.1 \mathrm{~m}$. Maps of the sea ice thickness and snow depth from the Arctic campaigns are shown in Figs. 12 and 13, while mean values are shown in Table 5. Histograms of the sea ice thickness and snow depth distributions for FY (first year) and MY (multi-year) ice are shown in Fig. 14. The maps show the varying spatial coverage of the data sets with increased coverage during the 2010 campaign due to a higher number of flight surveys. The snow depth maps show nearly full coverage over the flight tracks while the ice thickness maps show considerably less coverage due to (1) the absence of visible imagery for the detection of leads during much of Flight 3 ; (2) the absence of snow depth retrievals for Flight 1 (due to the higher transmit power and associated receiver saturation issues for this flight); and (3) the sporadic locations of leads necessary for accurate $\left(\sigma_{h_{f}}<0.1 \mathrm{~m}\right)$ freeboard retrievals. The increased number of flights since 2009 has led to the availability of more sea ice thickness data in each campaign.

The maps of snow depth show spatial gradients that are largely consistent with the expected pattern of snow distribution from observations (e.g., Warren et al., 1999). The deepest snow cover is found north of Greenland and the Canadian Archipelago with lower snow depths towards the Beaufort Sea region. As described in Kurtz and Farrell (2011), first year ice regions were found to have significantly less snow than multi-year ice regions, which is not reflected in the climatology of Warren et al. (1999) since the region was largely covered by multi-year ice when the observations were taken. This can also be seen in the snow thickness distributions in Fig. 14. For the 2009 campaign, the mean radar derived snow depth over the first year ice regions $(16.4 \mathrm{~cm})$ was observed to be $15 \mathrm{~cm}(48 \%)$ less than the mean snow depth over multi-year ice regions $(31.6 \mathrm{~cm})$, while for the 2010 campaign the mean snow depth over first year ice $(13.2 \mathrm{~cm})$ 


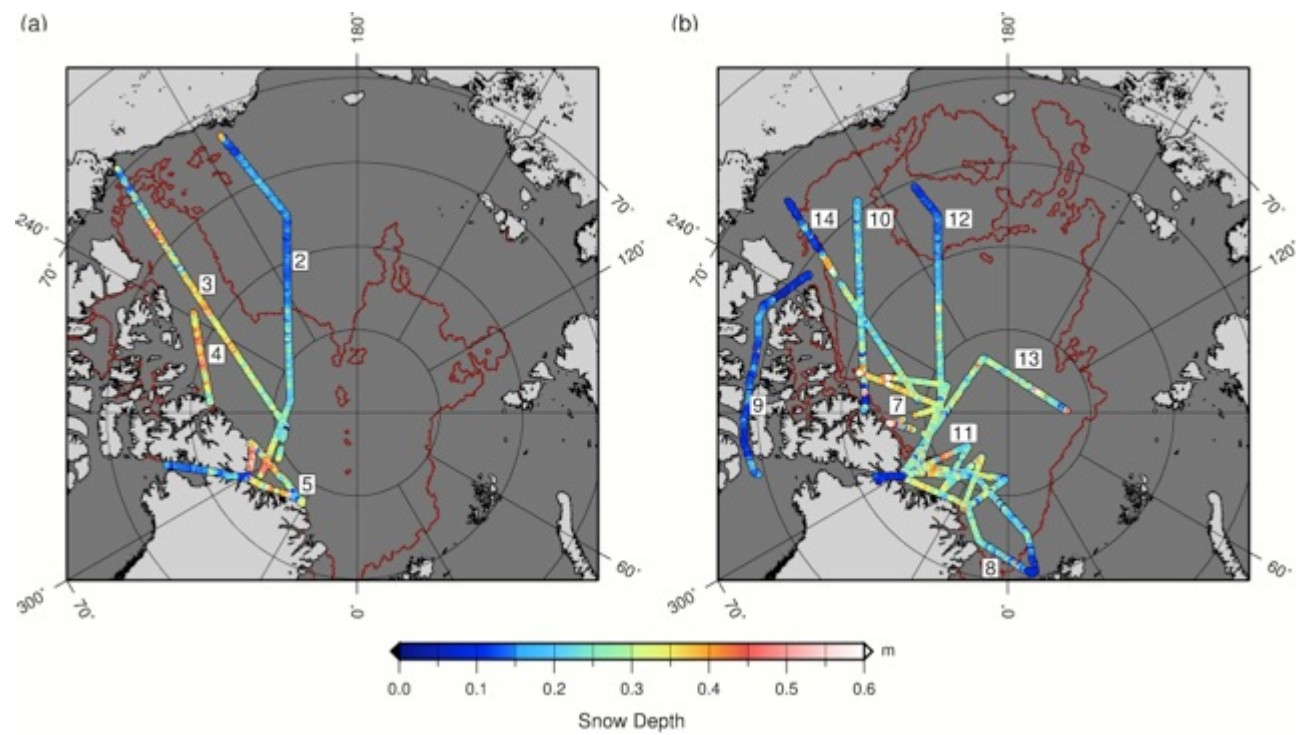

Fig. 12. Maps illustrating the along-track snow depth derived for the Arctic IceBridge campaigns for (a) 2009 and (b) 2010 . The red line corresponds to the multi-year ice boundary from the AMSR-E mask. The numbers correspond to the flight lines in Table 5.

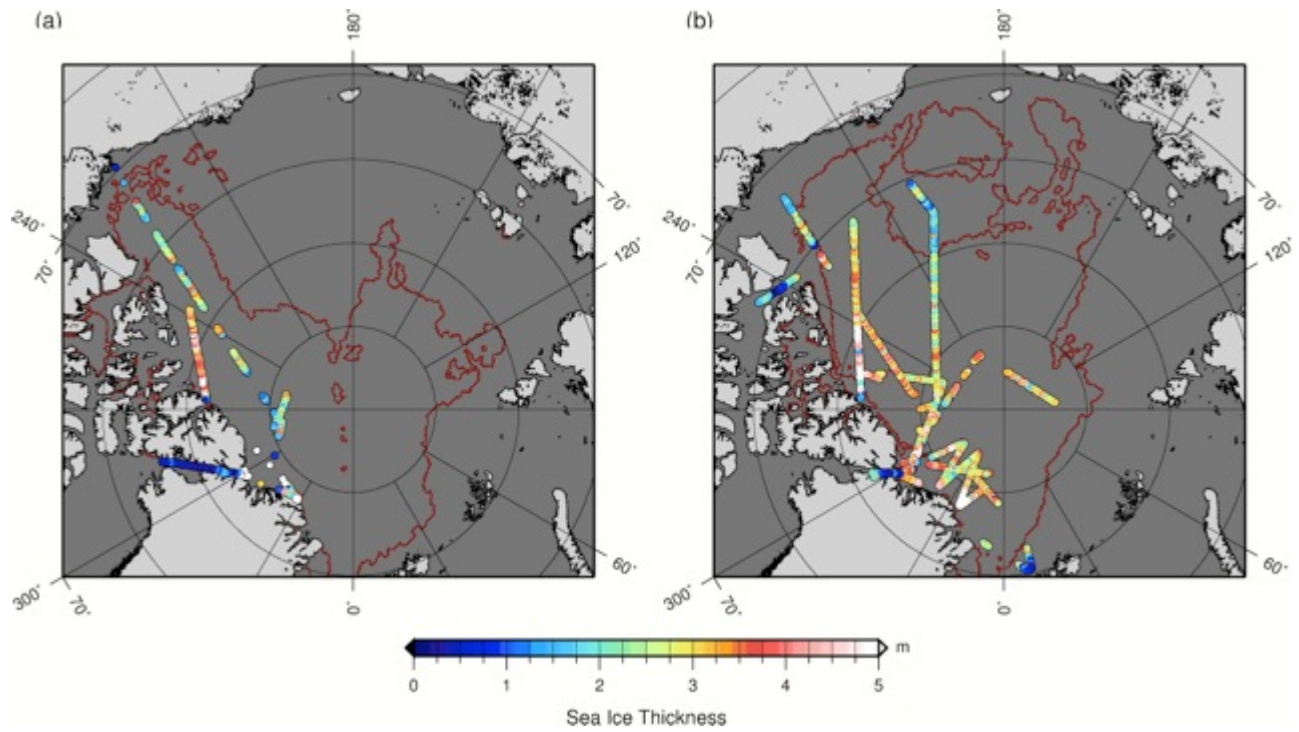

Fig. 13. Maps illustrating sea ice thickness for the Arctic IceBridge campaigns for (a) 2009 and (b) 2010. The red line corresponds to the multi-year ice boundary from the AMSR-E mask.

was $14 \mathrm{~cm}(52 \%)$ less than the mean snow depth over multiyear ice $(27.4 \mathrm{~cm})$. For multi-year ice, the mean snow depths are close to the climatology of Warren et al. (1999) (Kurtz and Farrell, 2011). The mean snow depth over first year ice is also broadly consistent with the mean snow depth from the AMSR-E snow depth on sea ice data product (Cavalieri et al., 2004). Gridding the IceBridge snow radar data to the same $12.5 \mathrm{~km}$ polar stereographic grid as AMSR-E results in mean differences (radar-AMSR-E) of $1.3 \mathrm{~cm}$ for the 2009 campaign and $-1.2 \mathrm{~cm}$ for the 2010 campaign. Farrell et al. (2012) found a mean difference of $0.8 \mathrm{~cm}$ between the
IceBridge derived snow depths and a $2 \mathrm{~km}$ in situ line of data during the 2009 campaign. We note that these comparisons of the radar derived mean snow depth values are not meant to supplant a more detailed study of the data sets and associated errors, but to show the snow depth estimates presented here are consistent with other independent data.

The ice thickness maps also show large-scale spatial gradients that are consistent with the expected pattern from recent observations (e.g., Haas et al., 2010; Kwok et al., 2009; Laxon et al., 2003; Wadhams et al., 2011; Laxon et al., 2013) and model results (e.g., Schweiger et al., 2011). The 

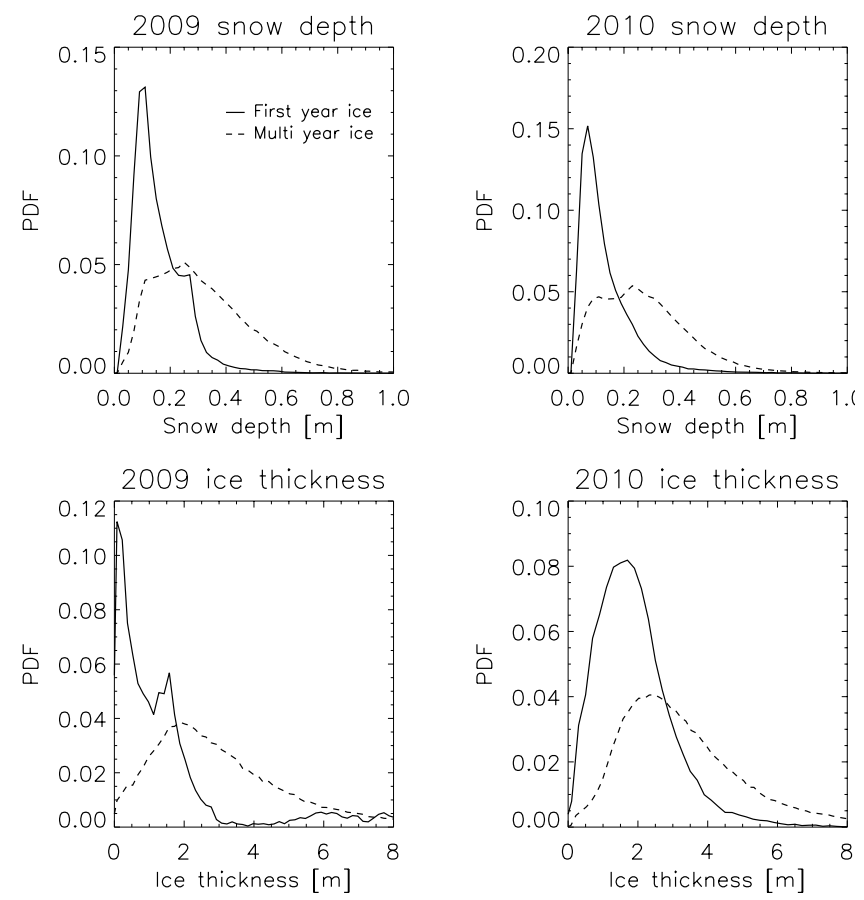

Fig. 14. Histograms of the ice and snow thickness distributions for the 2009 and 2010 campaigns separated into FY and MY ice components. The FY ice thickness data for the 2009 campaign are primarily from the Nares Strait region and are not necessarily representative of the FY ice thickness distribution from the Arctic basin.

thickest ice is observed north of Greenland and the Canadian Archipelago where the convergence of the sea ice pack due to the mean circulation pattern of the Arctic Ocean leads to the prevalence of heavily deformed and ridged thick ice. Away from the coastal areas and towards the Beaufort Sea region lower ice thickness values are observed. The thickness of first year ice has been observed to be significantly lower than that of multi-year ice, and this is reflected in the IceBridge data set. For the 2010 campaign (very few thickness observations are available for first year ice in the 2009 data set), the mean thickness of the first year ice area is $1.99 \mathrm{~m}$ while the mean thickness of the multi-year ice area is $3.36 \mathrm{~m}$.

We note that establishing the absolute accuracy of the IceBridge data set remains an ongoing effort, but here we compare the consistency of the results so as to provide support for the differences in inter-campaign retrieval methods as described in this document. In order to compare the consistency of the 2009 and 2010 results we have first gridded the IceBridge data to a $25 \mathrm{~km}$ polar stereographic grid. There were 38 grid points with spatial overlap corresponding mainly to Flights 2 and 3 for 2009, and the repeat Flights 12 and 14 for 2010. The mean thickness for the 2009 campaign overlapping grid points was $2.65 \mathrm{~m}$, while the mean thickness for the 2010 campaign was $2.61 \mathrm{~m}$. While we do expect differences due to interannual variability as well as ice motion, the con- sistency of the results is encouraging. Flights 4 and 10 further demonstrate the inter-campaign consistency of the retrieved results. These two flights were not exact repeats and thus not present in the previous comparison, but instead were closely spaced flight tracks that flew underneath the orbit of the Envisat satellite. Table 5 shows that we observed a large difference of $0.14 \mathrm{~m}$ in the mean snow depth between the 2009 and 2010 flights, but we also observed a large corresponding change of $0.16 \mathrm{~m}$ in the measured mean freeboard. The total difference in mean ice thickness was $0.18 \mathrm{~m}$. This difference is small considering the large mean differences in freeboard and snow depth and the independence of the two data sets.

Lastly, as a measure of the consistency within a campaign we compare overlapping $25 \mathrm{~km}$ grid points within the 2010 campaign data set (the 2009 campaign had only three overlapping grid points, which is not sufficient for a comparison). There were 58 overlapping grid points with snow depth measurements, the mean difference was $0.024 \mathrm{~m}$ with a standard deviation of $0.066 \mathrm{~m}$. This compares well with the expected uncertainty of $0.057 \mathrm{~m}$ reported earlier and expected differences (such as ice motion or snow fall events) due to the $\sim 1$ month time period over which the campaign was conducted. For ice thickness, there were 13 overlapping grid points with a mean difference of $0.22 \mathrm{~m}$ and a standard deviation of $0.78 \mathrm{~m}$. This also compares well with the mean uncertainty of the grid points, which was derived to be $0.70 \mathrm{~m}$, and also expected differences due to time offsets. Taken together, these results show that there is consistency in the IceBridge snow depth and sea ice thickness results in comparison to independent data sets as well as inter-campaign and intra-campaign consistency.

\section{Conclusions}

Here we have presented a description of the methods used to retrieve sea ice freeboard, thickness, and snow depth using a synthesis of instrument data from the IceBridge airborne platform. The derived products for the 2009 and 2010 IceBridge campaigns are currently available for public usage at http://nsidc.org/data/idcsi2.html. The methods described in this manuscript will also be applied for the retrieval of sea ice properties from the 2011 and 2012 campaigns and will also be made available through the National Snow and Ice Data Center. The inclusion of geolocated aerial photography, laser altimetry data, and snow radar data are all expected to be available throughout the IceBridge mission and thus the retrieval methods developed here will serve as a core processing methodology for future IceBridge campaigns. The inclusion of additional instruments is expected to lead to improved retrievals in subsequent years. For example, the KT19 infrared pyrometer was included in the 2012 IceBridge campaign and was set to use a sampling rate of $0.3 \mathrm{~Hz}$, which was higher than the $1 \mathrm{~Hz}$ sampling rate used in previous campaigns, this has the potential to improve the retrieval of sea 
ice freeboard by providing a method to discriminate sea ice leads when the sun is near or below the horizon and thus aerial photography is not available. This is an area of future research and any new retrieval method using the KT-19 data set will first be compared to the standard freeboard retrieval method that uses laser altimetry data and aerial photography described in this document.

Overall, we have shown there is consistency within the IceBridge snow depth and sea ice thickness results, and also shown there is consistency in comparison to other independent data sets. Linking the IceBridge data set to the sea ice thickness record, in particular to the records from satellite altimetry data such as ICESat, CryoSat-2, and ICESat-2, will require detailed knowledge of uncertainties in the data set. The evaluation and refinement of the accuracy of the IceBridge data set remains an ongoing effort especially with regard to the determination of the uncertainty at the $40 \mathrm{~m}$ length scale of the retrievals as well as the determination of any residual biases in the basin-scale data. This will be studied in future comparisons to other instruments and coincident in situ data from subsequent IceBridge campaigns.

Sea ice thickness and snow depth data derived using the core methodology described in this document have the potential to support a wide variety of research activities. A major ongoing effort is the connection of the IceBridge data set with the record of sea ice thickness retrievals from ICESat and CryoSat-2 to ensure that a consistent record of Arctic sea ice thickness is achievable from the satellite altimetry record. The results have also been used to support seasonal forecasting of the sea ice minimum and analyze the impact that initialized ice thicknesses have on the predictive capabilities of models (Lindsay et al., 2012). There is also potential for the evaluation and improvement of current snow depth retrieval methods such as those currently used from passive microwave data (Markus and Cavalieri, 1998; Cavalieri et al., 2012). Many other research efforts will benefit from the availability of such a data set and it is our goal to ensure that a consistent, and high quality, set of data products are produced to support the ongoing research goals of the cryospheric community.

Acknowledgements. The production of a sea ice and snow thickness product would not have been possible without the help of many people. We would like to thank the IceBridge Sea Ice Science Team and members of the community for support and guidance. We would also like to thank the instrument teams and air crews for long hours in the field and at home collecting and processing the data and the National Snow and Ice Data Center for archiving and publishing the data. This work is funded by NASA's Airborne Science and Cryospheric Sciences Programs.

Edited by: J. Stroeve

\section{References}

Alexandrov, V., Sandven, S., Wahlen, J., and Johannessen, O. M.: The relation between sea ice thickness and freeboard in the Arctic, The Cryosphere, 4, 373-380, doi:10.5194/tc-4-373-2010, 2010.

Barber, D. G., Reddan, S. P., and Ledrew, E. F.: Statistical characterization of the geophysical and electrical properties of snow on landfast first-year sea ice, J. Geophys. Res., 100, C2, 2673-2686, 1995.

Carsey, F. D. (Ed.): Microwave Remote Sensing of Sea Ice, Geophys. Monogr. Ser., Vol. 68, 462 pp., AGU, Washington D.C., 1992.

Cavalieri, D. J. and Markus, T.: EOS Aqua AMSR-E Arctic sea ice validation program: Arctic 2006 aircraft campaign flight report, NASA/TM-2006-214142, 27 pp., 2006.

Cavalieri, D. J., Markus, T. and Comiso, J. C.: AMSR-E/Aqua Daily L3 12.5 km Brightness Temperature, Sea Ice Concentration, and Snow Depth Polar Grids V002, (31 March 2009 to 21 April 2010), Digital media, National Snow and Ice Data Center, Boulder, Colorado USA, 2004.

Cavalieri, D. J., Markus, T., Ivanoff, A., Miller, J. A., Brucker, L., Sturm, M., Maslanik, J. A., Heinrichs, J. F., Gasiewski, A. J., Leuschen, C., Krabill, W., and Sonntag, J.: A Comparison of Snow Depth on Sea Ice Retrievals Using Airborne Altimeters and an AMSR-E Simulator, IEEE Trans. Geosc. Rem. Sens., 50, 3027-3040, doi:10.1109/TGRS.2011.2180535, 2012.

Chelton, D. B., Ries, J. C., Haines, B. J., Fu, L., and Callahan, P. S.: Satellite altimetry, in Satellite Altimetry and Earth Sciences, Int. Geophys. Ser., 19, Elsevier, New York, 2001.

Chelton, D. B., deSzoeke, R. A., Schlax, M. G., El Naggar, K., and Siwertz, N.: Geographical Variability of the First Baroclinic Rossby Radius of Deformation. J. Phys. Oceanogr., 28, 433-460, 1998.

Comiso, J. C., Cavalieri, D. J., and Markus, T.: Sea ice concentration, ice temperature, and snow depth using AMSR-E data, IEEE Trans. Geosci. Remote Sens., 41, 243-252, 2003.

Connor, L. N., Laxon, S., Ridout, A. L., Krabill, W. B., and McAdoo, D. C.: Comparison of Envisat radar and airborne laser altimeter measurements over Arctic sea ice, Remote Sens. Environ., 113, 563-570, doi:10.1016/j.rse.2008.10.015, 2009.

Connor, L. N., Farrell, S. L., McAdoo, D. C., Krabill, W. B., and Manizade, S.: Validating ICESat over thick sea ice in the Northern Canada basin, IEEE Trans. Geosci. Remote, 99, 1-13, doi:10.1109/TGRS.2012.2211603, 2012.

Cressie, N.: Statistics for spatial data, Wiley Interscience, 1993.

Dominguez, R.: IceBridge DMS L1B Geolocated and Orthorectified Images, (23 March 2010 - 21 April 2010), Digital media, National Snow and Ice Data Center, Boulder, Colorado USA, 2009.

Doble, M. J., Skourup, H., Wadhams, P., and Geiger, C. A.: The relation between Arctic sea ice surface elevation and draft: a case study using coincident AUV sonar and airborne scanning laser, J. Geophys. Res., 116, C00E03, doi:10.1029/2011JC007076, 2011.

Egbert, G. D. and Erofeeva, L.: Efficient inverse modeling of barotropic ocean tides, J. Atmos. Ocean. Tec., 19, N2, 183-204, 2002.

Eicken, H., Lensu, M., Lepparanta, M., Tucker, W. B., Gow, A. J., and Salmela, O.: Thickness, structure and properties of level summer multiyear ice in the Eurasian sector of the Arctic 
Ocean, J. Geophys. Res., 100, 22697-22710, 1995.

Farrell, S. L., Kurtz, N. T., Connor, L., Elder, B., Leuschen, C., Markus, T., McAdoo, D. C., Panzer, B., Richter-Menge, J., and Sonntag, J.: A First Assessment of IceBridge Snow and Ice Thickness Data over Arctic Sea Ice, IEEE Trans. Geosc. Rem. Sens., 50, doi:10.1109/TGRS.2011.2170843, 2012.

Farrell, S. L., Laxon, S. W., McAdoo, D. C., Yi, D., and Zwally, H. J.: Five years of Arctic sea ice freeboard measurements from the ice, cloud and land elevation satellite, J. Geophys. Res., 114, C04008, doi:10.1029/2008JC005074, 2009.

Försstrom, S., Gerland, S., and Pedersen, C. A.: Thickness and density of snow-covered sea ice and hydrostatic equilibrium assumption from in situ measurements in Fram Strait, the Barents Sea and the Svalbard coast, Ann. Glaciol., 52, 261-270, 2011.

Galin, N., Worby, A., Markus, T., Leuschen, C., and Gogineni, P.: Validation of airborne FMCW radar measurements of snow thickness over sea ice in Antarctica, IEEE Trans. Geosci. Rem. Sens., 50, 3-12, doi:10.1109/TGRS.2011.2159121, 2012.

Giles, K. A., Laxon, S. W., and Ridout, A. L.: Circumpolar thinning of Arctic sea ice following the 2007 record ice extent minimum, Geophys. Res. Lett., 35, L22502, 2008a.

Giles, K. A., Laxon, S. W., and Worby, A. P.: Antarctic sea ice elevation from satellite radar altimetry, Geophys. Res. Lett., 35, L03503, doi:10.1029/2007GL031572, 2008b.

Haas, C., Hendricks, S., Eicken, H., and Herber, A.: Synoptic airborne thickness surveys reveal state of Arctic sea ice cover, Geophys. Res. Lett., 37, L09501, doi:10.1029/2010GL042652, 2010.

Kovacs, A.: Sea ice: Part II, Estimating the full-scale tensile, flexural, and compressive strength of first-year ice, CRREL Rep. 9611, Cold Reg. Res. and Eng Lab., Hanover, NH, 1996.

Krabill, W. B., Thomas, R. H., Martin, C. F., Swift, R. N., and Frederick, E. B.: Accuracy of airborne laser altimetry over the Greenland ice sheet, Int. J. Rem. Sens., 16, 1211-1222, 1995.

Krabill, W. B.: IceBridge ATM L1B Qfit elevation and return strength, (23 March 2009 - 21 April 2010), Digital Media, National Snow and Ice Data Center, Boulder, Colorado USA, 2009a.

Krabill, W. B.: IceBridge CAMBOT L1B geolocated images, (31 March 2009 - 25 April 2009), Digital media, National Snow and Ice Data Center. Digital media, Boulder, Colorado USA, 2009b.

Kurtz, N. T. and Farrell, S. L.: Large-scale surveys of snow depth on Arctic sea ice from operation IceBridge, Geophys. Res. Lett., 38, L20505, doi:10.1029/2011GL049216, 2011.

Kurtz, N. T., Markus, T., Cavalieri, D. J., Krabill, W., Sonntag, J. G., and Miller, J.: Comparison of ICESat data with airborne laser altimeter measurements over Arctic sea ice, IEEE Trans. Geosci. Remote, 46, 1913-1924, 2008.

Kurtz, N. T., Markus, T., Cavalieri, D. J., Sparling, L. C., Krabill, W. B., Gasiewski, A. J., and Sonntag, J. G.: Estimation of sea ice thickness distributions through the combination of snow depth and satellite laser altimetry data, J. Geophys. Res., 114, C10007, doi:10.1029/2009JC005292, 2009.

Kurtz, N. T., Markus, T., Farrell, S. L., Worthen, D. L., and Boisvert, L. N.: Observations of recent Arctic sea ice volume loss and its impact on ocean-atmosphere energy exchange and ice production, J. Geophys. Res., 116, C04015, doi:10.1029/2010JC006235, 2011.

Kurtz, N., Studinger, M., Harbeck, J., Onana, V., and Farrell, S.: IceBridge Sea Ice Freeboard, Snow Depth, and Thickness, (31
March 2009 - 21 April 2010), Digital media, NASA Distributed Active Archive Center at the National Snow and Ice Data Center, Boulder, Colorado USA, available at: http://nsidc.org/data/ idcsi2.html, 2012.

Kurtz, N. T. and Markus, T.: Satellite observations of Antarctic sea ice thickness and volume, J. Geophys. Res., 117, C08025, doi:10.1029/2012JC008141, 2012.

Kwok, R., Cunningham, G. F., Wensnahan, M., Rigor, I., Zwally, H. J., and Yi, D.: Thinning and volume loss of the Arctic Ocean sea ice cover: 2003-2008, J. Geophys. Res., 114, C07005, doi:10.1029/2009JC005312, 2009.

Kwok, R., Panzer, B., Leuschen, C., Pang, S., Markus, T., Holt, B., and Gogineni, S.: Airborne surveys of snow depth over Arctic sea ice,J. Geophys. Res., 116, C11018, doi:10.1029/2011JC007371, 2011.

Kwok, R., Cunningham, G. F., Manizade, S. S., and Krabill, W. B.: Arctic sea ice freeboard from IceBridge acquisitions in 2009: Estimates and comparisons with ICESat, J. Geophys. Res., 117, C2, doi:10.1029/2011JC007654, 2012.

Laxon, S., Giles, K. A., Ridout, A. L., Wingham, D. J., Willatt, R., Cullen, R., Kwok, R., Schweiger, A., Zhang, J., Haas, C., Hendricks, S., Krishfield, R., Kurtz, N., Farrell, S., and Davidson, M.: CryoSat-2 estimates of Arctic sea ice thickness and volume, Geophys. Res. Lett., 40, doi:10.1002/grl.50193, 2013.

Laxon, S., Peacock, N., and Smith, D.: High interannual variability of sea ice thickness in the Arctic region, Nature, 425, 947-950, 2003.

Lemke, P., Ren, J., Alley, R. B., Allison, I., Carrasco, J., Flato, G., Fujii, Y., Kaser, G., Mote, P., Thomas, R. H., and Zhang, T.: Observations: Changes in Snow, Ice and Frozen Ground, in: Climate Change 2007: The Physical Science Basis, Contribution of Working Group I to the Fourth Assessment Report of the Intergovernmental Panel on Climate Change, edited by: Solomon, S., Qin, D., Manning, M., Chen, Z., Marquis, M., Averyt, K. B., Tignor, M., and Miller, H. L., Cambridge University Press, Cambridge, United Kingdom and New York, NY, USA, 2007.

Leuschen, C. J., Swift, R. N., Comiso, J. C., Raney, R. K., Chapman, R. D., Krabill, W. B., and Sonntag, J. G.: Combination of laser and radar altimeter height measurements to estimate snow depth during the 2004 Antarctic AMSRE sea ice field campaign, J. Geophys. Res., 113, C04S90, doi:10.1029/2007JC004285, 2008.

Leuschen, C.: IceBridge snow radar L1B geolocated radar echo strength profiles, (23 March 2009 - 21 April 2010), Digital media, National Snow and Ice Data Center, Boulder, Colorado USA, 2009.

Lindsay, R., Hass, C., Hendricks, S., Hunkeler, P., Kurtz, N. T., Paden, J., Panzer, B., Sonntag, J., Yungel, J., and Zhang, J.: Seasonal forecasts of arctic sea ice initialized with observations of ice thickness, Geophys. Res. Lett., doi:10.1029/2012GL053576, 2012.

Markus, T. and Cavalieri, D. J.: Snow depth distribution over sea ice in the Southern Ocean from satellite passive microwave data, in Antarctic Sea Ice Physical Processes, Interactions and Variability, Antarctic Research Series, 74, edited by: Jeffries, M. O., 19-40, AGU, Washington, D.C, 1998.

Martin, C. F., Krabill, W. B., Manizade, S., Russell, R., Sonntag, J. G., Swift, R. N., and Yungel, J. K.: Airborne Topographic Mapper Calibration Procedures and Accuracy As- 
sessment, NASA Technical Reports, Vol. 20120008479(NASA/ TM-2012-215891, GSFC.TM.5893.2012), http://hdl.handle.net/ 2060/20120008479, 32 pp., Natl. Aeronaut. and Space Admin., Washington, D. C, 2012.

Massom, R. A., Eicken, H., Haas, C., Jeffries, M. O., Drinkwater, M. R., Sturm, M., Worby, A. P., Wu, X., Lytle, V. I., Ushio, S., Morris, K., Reid, P. A., Warren, S. G., and Allison, I.: Snow on Antarctic sea ice, Rev. Geophys., 39, 413-445, 2001.

Onana, V. D., Kurtz, N.T., Farrell, S.L., Koenig, L.S., Studinger, M., and Harbeck, J.P.: A Sea-Ice Lead Detection Algorithm for Use With High-Resolution Airborne Visible Imagery, IEEE Trans. Geosc. Rem. Sens., 51, 38-56, doi:10.1109/TGRS.2012.2202666, 2013.

Panzer, B., Leuschen, C., Patel, A., Markus, T., and Gogineni, P.: Ultra-wideband radar measurements of snow thickness over sea ice, Proc. 2010 IEEE International Geoscience and Remote Sensing Symposium (IGARSS), Honolulu, HI, 25-30 July 2010, 3130-3133, doi:10.1109/IGARSS.2010.5654342, 2010.

Panzer, B., Gomez-Garcia, D., Leuschen, C., Paden, J., RodriguezMorales, F., Patel, A., Markus, T., Holt, B., and Gogineni, P.: An ultra-wideband, microwave radar for measuring snow thickness on sea ice and mapping near-surface internal layers in polar firn, J. Glaciol., 59, 244-254, doi:10.3189/2013JoG12J128, 2013.

Pavlis, N. K., Holmes, S. A., Kenyon, K. C., and Factor, J. K.: An Earth Gravitational Model to Degree 2160: EGM2008, presented at the 2008 General Assembly of the European Geosciences Union, Vienna, Austria, April 13-18, 2008.

Raney, R. K.: The delay/Doppler radar altimeter, IEEE Trans. Geosc. Rem. Sens., 36, 5, 1578-1588, doi:10.1109/36.718861, 1998.

Schenk, T., Csatho, B. M., and Lee, D.-C.: Quality control issues of airborne laser ranging data and accuracy study in an urban area, Int. Arch. Photo. Rem. Sens., 32, 101-108, 1999.

Schweiger, A., Lindsay, R., Zhang, J., Steele, M., Stern, H., and Kwok, R.: Uncertainty in modeled Arctic sea ice volume, J. Geophys. Res., 116, C00D06, doi:10.1029/2011JC007084, 2011.

Shetter, R., Buzay, E., and Van Gilst, D.: updated current year, IceBridge NSERC L1B Geolocated Meteorologic and Surface Temperature Data, [Mar. 23-Apr. 21, 2010]. Boulder, Colorado USA: NASA Distributed Active Archive Center at the National Snow and Ice Data Center. Digital media. http://nsidc.org/data/iamet1b. html, 2010.
Timco, G. W. and Frederking, R. M. W.: A review of sea ice density, Cold Reg. Sci. Tech., 24, 1-6, 1996.

Tiuri, M., Sihvola, A., Nyfors, E., and Hallikainen, M.: The complex dielectric constant of snow at microwave frequencies, IEEE J. Oceanic Eng., 9, 377-382, 1984.

Wadhams, P., Hughes, N., and Rodrigues, J.: Arctic sea ice thickness characteristics in winter 2004 and 2007 from submarine sonar transects, J. Geophys. Res., 116, C00E02, doi:10.1029/2011JC006982, 2011.

Wadhams, P., Davis, N. R.,Comiso, J. C., Kutz, R., Crawford, J., Jackson, G., Krabill, W., Sear, C. B., Swift, R., and Tucker III, W. B.: Concurrent remote sensing of Arctic sea ice from submarine and aircraft, Int. J. Rem. Sens., 12, 1829-1840, doi:10.1080/01431169108955212, 1991.

Wadhams, P., Tucker III, W. B., Krabill, W. B., Swift, R. N., Comiso, J. C., and Davis, N. R.: Relationship between sea ice freeboard and draft in the Arctic basin, and implications for ice thickness monitoring, J. Geophys. Res., 97, 20325-20334, 1992.

Warren, S. G., Rigor, I. G., Untersteiner, N., Radionov, V. F., Bryazgin, N. N., Aleksandrov, Y. I., and Colony, R.: Snow depth on Arctic sea ice, J. Climate, 12, 1814-1829, 1999.

Wahr J. M.: Deformation induced by polar motion, J. Geophys. Res., 90, 9363-9368, 1985.

Willatt, R. C., Giles, K. A., Laxon, S. W., Stone-Drake, L., and Worby, A. P., Field Investigations of Ku-Band Radar Penetration Into Snow Cover on Antarctic Sea Ice, IEEE Trans. Geosc. Rem. Sens., 48, 365-372, doi:10.1109/TGRS.2009.2028237, 2010.

World Meteorological Organization, Sea ice nomenclature: Terminology, Codes and Illustrated Glossary, WMO/OMM/BMO 259, TP 145, World Meteorological Organization, Geneva, 1970.

Zwally, H.J., Yi, D., Kwok, R., and Zhao, Y.: ICESat measurements of sea ice freeboard and estimates of sea ice thickness in the Weddell Sea, J. Geophys. Res., 113, C02S15, doi:10.1029/2007JC004284, 2008. 